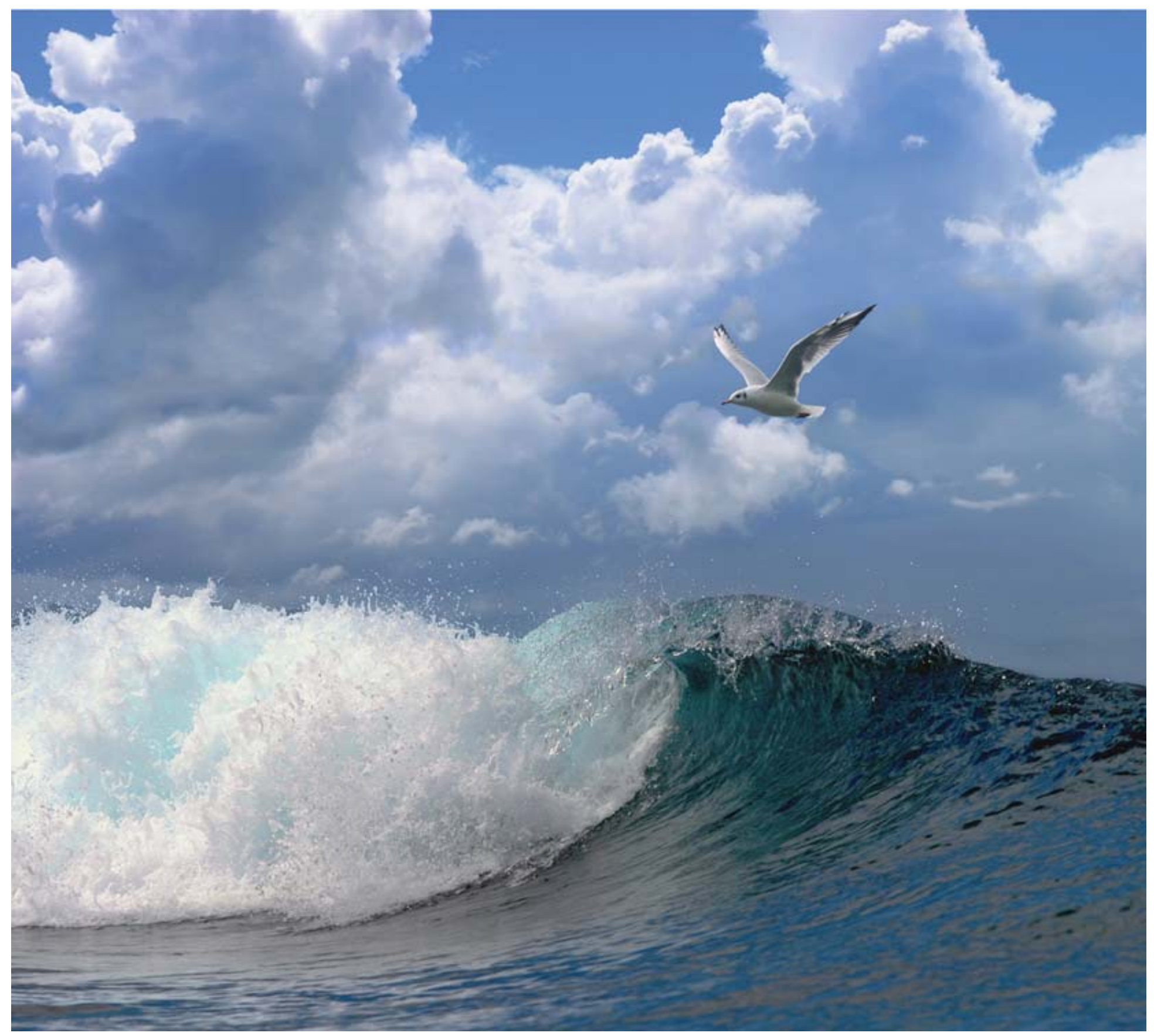

\title{
Resultaten van het Rijkswaterstaat J AMP 2016 monitoringsprogramma van milieukritische stoffen in schelpdieren
}





\section{Resultaten van het Rijkswaterstaat J AMP 2016 monitoringsprogramma van milieukritische stoffen in schelpdieren}


Sneekes A.C. \& M. Tjon Atsoi (2017). Resultaten van het Rijkswaterstaat JAMP 2016

monitoringsprogramma van milieukritische stoffen in schelpdieren. Wageningen Marine Research Wageningen UR (University \& Research centre), Wageningen Marine Research rapport C029/17.

Keywords: Mytlilus edulis, Crassostrea gigas, monitoring, contaminants metals

\author{
Opdrachtgever: Rijkswaterstaat \\ T.a.v.: M. Roos \\ Postbus 17 \\ 8200 AA Lelystad
}

Dit rapport is vanaf 6 maanden na publicatie gratis te downloaden van

https://doi.org/10.18174/412007

Wageningen Marine Research verstrekt geen gedrukte exemplaren van rapporten.

Wageningen Marine Research Wageningen UR is ISO 9001: 2008 gecertificeerd.

\title{
(C) 2017 Wageningen Marine Research Wageningen UR
}

Wageningen Marine Research, onderdeel van Stichting Wageningen Research KvK nr. 09098104,

IMARES BTW nr. NL 8113.83.696.B16. Code BIC/SWIFT address: RABONL2U IBAN code: NL 73 RABO 0373599285
De Directie van Wageningen Marine Research is niet aansprakelijk voor gevolgschade, noch voor schade welke voortvloeit uit toepassingen van de resultaten van werkzaamheden of andere gegevens verkregen van Wageningen Marine Research opdrachtgever vrijwaart Wageningen Marine Research van aanspraken van derden in verband met deze toepassing. Dit rapport is vervaardigd op verzoek van de opdrachtgever hierboven aangegeven en is zijn eigendom. Niets uit dit rapport mag weergegeven en/of gepubliceerd worden, gefotokopieerd of op enige andere manier gebruikt worden zonder schriftelijke toestemming van de opdrachtgever. 


\section{Inhoud}

$\begin{array}{lr}\text { Samenvatting } & 4\end{array}$

$\begin{array}{llr}1 & \text { Inleiding } & 5\end{array}$

2 Werkzaamheden $\quad 6$

$\begin{array}{llr}3 & \text { Methoden } & 7\end{array}$

$\begin{array}{lll}3.1 & \text { Bemonstering schelpdieren } & 7\end{array}$

3.2 Analysemethoden $\quad 8$

$\begin{array}{ll}3.2 .1 & \text { PCB's en OCP's } \\ 3.2 .2 & 10\end{array}$

$\begin{array}{ll}3.2 .2 & \text { PBDE'S en HBCD } \\ 3.2 .3 & 10\end{array}$

$\begin{array}{lll}3.2 .3 \text { Kwik } & 10\end{array}$

3.2.4 Koper, cadmium, lood, zink, chroom, arseen, nikkel 11

$\begin{array}{ll}3.2 .5 \text { PAK's } & 11\end{array}$

3.2.6 Droge stof/as 11

$\begin{array}{lll}3.2 .7 \text { Vet } & 11\end{array}$

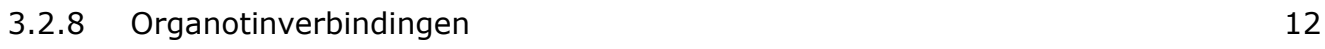

3.2.9 Perfluorverbindingen $\quad 12$

$\begin{array}{ll}3.3 & \text { Dataopslag en -registratie } \\ \end{array}$

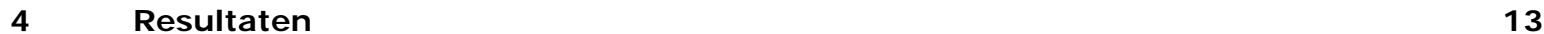

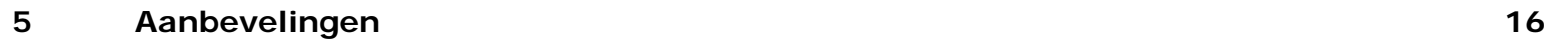

$\begin{array}{llr}6 & \text { Literatuur } & 17\end{array}$

$\begin{array}{llr}7 & \text { Kwaliteitsborging } & 18\end{array}$

$\begin{array}{lr}\text { Verantwoording } & 19\end{array}$

$\begin{array}{lr}\text { BI J LAGE } 1 \mathrm{t} / \mathrm{m} \mathbf{8 . 3} & \mathbf{2 0}\end{array}$ 


\section{Samenvatting}

In opdracht van Rijkswaterstaat zijn door Wageningen Marine Research werkzaamheden uitgevoerd in het kader van het Joint Assessment and Monitoring Program van de OSPARCOM.

In dit project, gebaseerd op het door RWS aangeleverde werkdocument "Monitoring chemische stoffen in mariene schelpdieren 2015, meetplan chemisch meetnet MWTL", worden schelpdieren van twee locaties, Westerschelde en de Eems-Dollard, onderzocht op de gehalten van milieukritische stoffen, zowel organische contaminanten als metalen. Deze schelpdieren worden door RWS aangeleverd in vijf lengteklassen. De beschikbaarheid van grote Blauwe mosselen, Mytilus edulis, in de Westerschelde is echter laag, mede door verdringing door de Japanse oester, Crassostrea gigas. In de Eems-Dollard zijn alle klassen mosselen schaars. Het gebruik van de Japanse oester als monitoringsalternatief voor de Blauwe mossel is in overeenstemming met het OSPAR CEMP/JAMP-programma. Daarom kunnen als alternatief voor de Blauwe mosselen ook Japanse oesters worden bemonsterd. Vanaf 2014 zijn ook de componenten heptachloor, HBCD en de perfluorverbindingen aan de te analyseren lijst milieukritische stoffen toegevoegd, vanwege Richtlijn 2013/39/EU die 12 augustus 2013 is gepubliceerd en rechtsgeldig wordt vanaf 2018 .

De werkzaamheden zijn in 2016 wederom volgens RWS protocol uitgevoerd, met de kanttekening dat de grootste lengteklasse mosselen voor de locatie Westerschelde niet is geleverd. Het mogelijke alternatief, de Japanse oester, is ook aangeleverd. In de locatie Eems-Dollard werden ook dit jaar onvoldoende mosselen aangetroffen, daarom is in overleg met RWS besloten ook dit jaar weer de Japanse Oesters te analyseren. Dit is afwijkend van het oorspronkelijke projectplan. De analyseresultaten laten grote verschillen zien tussen de Eems Dollard en de Westerschelde, ten dele veroorzaakt door de verschillen in opname door mossel en oester. In de Westerschelde, waar beide soorten zijn geanalyseerd, is duidelijk te zien dat oesters hogere gehalten metalen als koper en zink bevatten dan de mosselen, terwijl de gehalten PCBs in de mossel hoger zijn De resultaten zijn in tabelvorm als bijlagen achter in dit rapport bijgevoegd en worden als DIF-files aangeleverd voor opslag in DONAR. 


\section{$1 \quad$ Inleiding}

De in dit rapport beschreven werkzaamheden zijn door Wageningen Marine Research uitgevoerd op basis van een opdracht van Rijkswaterstaat (RWS) in het kader van het Joint Assessment and Monitoring Program van de OSPARCOM. De opdracht is gebaseerd op het door RWS aangeleverde concept werkdocument "Monitoring chemische stoffen in mariene schelpdieren 2015, meetplan chemisch meetnet MWTL", van 15 april 2015. Een definitief meetplan voor 2016 is niet verstrekt.

Door RWS zijn schelpdieren (mosselen en Japanse oesters) afkomstig van twee locaties aangeleverd (Westerschelde en Eems-Dollard). De schelpdieren zijn gekarakteriseerd, waarna schelpdiervlees is verzameld voor het chemisch onderzoek door Wageningen Marine Research. Tevens is schelpdiervlees verzameld voor het bepalen van de radiochemische samenstelling.

Vanuit RWS werd het programma geleid door mevr. A Houben, vanuit Wageningen Marine Research was Dr. M. Kotterman projectleider.

Bij Wageningen Marine Research werden de organisch chemische analyses en de analyses van kwik, vocht en as uitgevoerd. De overige analyses van metalen zijn uitgevoerd door TNO Triskelion, Utrechtseweg 48, $3704 \mathrm{HE}$ te Zeist. Het bepalen van de radiochemische samenstelling behoorde niet tot de opdracht van Wageningen Marine Research. Deze analyses zijn uitgevoerd door het laboratorium van Rijkswaterstaat en worden derhalve niet in dit rapport vermeld. 


\section{Werkzaamheden}

In het kader van de hierboven genoemde opdracht zijn door Wageningen Marine Research de volgende werkzaamheden uitgevoerd:

1. Karakteriseren schelpdiermonsters en verzamelen schelpdiervlees voor chemische analyses

2. Het uitvoeren van chemische analyses

3. Het verzamelen schelpdiervlees voor radiochemische analyses

4. Het rapporteren van de verkregen resultaten

5. Het genereren van DONAR-files

Afwijkingen van het door RWS aangeleverde meetplan:

Door RWS zijn geen oesters afkomstig van de Westerschelde en geen mosselen afkomstig van de Eems-Dollard aangeleverd. Ook ontbrak de grootste lengteklasse mosselen afkomstig van de Westerschelde. 


\section{$3 \quad$ Methoden}

\subsection{Bemonstering schelpdieren}

Mosselen en Japanse oesters uit de Westerschelde en Japanse oesters uit de Eemsmonding zijn op 25 november 2016 diepgevroren aangeleverd door RWS bij het laboratorium van Wageningen Marine research in IJmuiden.

De onderzoeklocaties zijn weergegeven in Tabel 1.

Tabel $1 \quad$ Onderzoeklocaties; chemie

\begin{tabular}{|l|l|l|l|l|}
\hline Gebied & $\begin{array}{l}\text { Locatiecode } \\
\text { DONAR }\end{array}$ & \multicolumn{2}{|l|}{ Coördinaten } & MID-RWS \\
\hline $\begin{array}{l}\text { Eems-Dollard: } \\
\text { Bocht van Watum }\end{array}$ & BOCHTVWTM & $254.000^{\text {RDx }}$ & $604.455^{\text {RDy }}$ & Noord-Nederland \\
\hline $\begin{array}{l}\text { Westerschelde: } \\
\text { Knuitershoek }\end{array}$ & KNUITHK & 55.850 RDx & 379.950 RDy & Zeeland \\
\hline
\end{tabular}

Voor de chemische analyse van de mosselen wordt ernaar gestreefd vijf lengteklassen 25-31, 32-38, 39-47, 48-57, 58-70 $\mathrm{mm}$ te verzamelen voor het verkrijgen van minimaal 300 gram mosselvlees per lengteklasse. In bijlage 1 worden analysenummers, schelplengtes en gewichten en tevens vleesgewicht van de mosselen gegeven. De grootste klasse is al gedurende meerdere jaren moeilijk te verkrijgen uit beide gebieden. Dit jaar zijn er geen mosselen van deze klasse 5 (58-70 mm) uit de Westerschelde geleverd. De mosselen voor de lengteklasse $1 \mathrm{t} / \mathrm{m} 3$ waren voor de locatie Westerschelde in voldoende aantallen aanwezig voor samenstelling van representatieve monsters, lengteklasse 4 bedroeg slechts 46 mosselen. Door het gebrek aan monstermateriaal konden niet alle analyses uitgevoerd worden, BDEs, PFOS en organotin zijn niet geanalyseerd.

Uit de Eems-Dollard zijn dit jaar helemaal geen mosselen aangeleverd.

Wel zijn Japanse oesters, afkomstig van de Eems-Dollard, aangeleverd. Het oorspronkelijke projectplan voorzag erin de oesters alleen te karakteriseren en analyses tot nader order achterwege te laten, maar bij gebrek aan voldoende mosselmateriaal is in overleg met de RWS besloten tevens chemische analyses in de oesters uit te voeren. Dit was niet van invloed op het beschikbare budget. Hiertoe zijn 3 monsters van tenminste 25 at random gekozen oesters uit de aangeleverde hoeveelheid genomen, zodanig dat voor elk monster tenminste 300 gram monstermateriaal beschikbaar kwam voor chemische analyses. In bijlage 1 worden analysenummers, schelplengtes en gewichten en tevens vleesgewicht van de oesters gegeven.

Tevens is t.b.v. radiochemische analyses van de aanwezige mosselen (4 monsters Westerschelde) en oesters ( 3 monsters Eems-Dollard, drie monsters Westerschelde) tenminste 50 gram per monster verzameld. Deze monsters zijn door een koerier, geregeld door RWS, bij Wageningen Marine Research opgehaald. Het uitvoeren van de radiochemische analyses viel niet onder opdracht van Wageningen Marine Research. Deze analyses worden uitgevoerd door het laboratorium van Rijkswaterstaat. 


\subsection{Analysemethoden}

De volgende chemische componenten zijn geanalyseerd en gerapporteerd:

\begin{tabular}{|c|c|c|c|}
\hline Component & Rapport & Donar-code & CAS-nummer \\
\hline Percentage droge stof & Droge stof $\%$ & $\% \mathrm{DS}$ & n.v.t. \\
\hline Percentage gloeiverlies & AVDG & $\% \mathrm{GV}$ & n.v.t. \\
\hline Percentage gloeirest & As & $\% G R$ & n.v.t. \\
\hline Vet: totaal B\&D & Vet $B \& D$ & VET & n.v.t. \\
\hline Vet: vrij extraheerbaar (Soxhlet) & Vet Soxhlet & n.v.t. & n.v.t. \\
\hline Arseen & Arseen & As & $7440-38-2$ \\
\hline Kwik & Kwik & $\mathrm{Hg}$ & $7439-97-6$ \\
\hline Cadmium & Cadmium & $\mathrm{Cd}$ & $7440-43-9$ \\
\hline Chroom & Chroom & $\mathrm{Cr}$ & $7440-47-3$ \\
\hline Koper & Koper & $\mathrm{Cu}$ & $7440-50-8$ \\
\hline Nikkel & Nikkel & $\mathrm{Ni}$ & $7440-02-0$ \\
\hline Lood & Lood & $\mathrm{Pb}$ & 7439-92-1 \\
\hline Zink & Zink & $\mathrm{Zn}$ & $7440-66-6$ \\
\hline Benzo(b)fluoranteen & Benzo(b)fluoranteen & $\mathrm{BbF}$ & $205-99-2$ \\
\hline Benzo(k)fluoranteen & Benzo(k)fluoranteen & $\mathrm{BkF}$ & $207-08-9$ \\
\hline Fluoranteen & Fluoranteen & Flu & $206-44-0$ \\
\hline Benzo(a)pyreen & Benzo(a)pyreen & $\mathrm{PaP}$ & $50-32-8$ \\
\hline Benzo $(g, h, i)$ peryleen & Benzo $(g, h, i)$ peryleen & BghiPe & $191-24-2$ \\
\hline Indeno $(1,2,3-c, d)$ pyreen & Indeno $(1,2,3-c, d)$ pyreen & InP & $193-39-5$ \\
\hline Fenanthreen & Fenanthreen & Fen & $85-01-8$ \\
\hline Anthraceen & Anthraceen & Ant & $120-12-7$ \\
\hline Benzo(a)anthraceen & Benzo(a)anthraceen & $\mathrm{BaA}$ & $56-55-3$ \\
\hline Chryseen & Chryseen & $\mathrm{Chr}$ & $218-01-9$ \\
\hline Pyreen & Pyreen & Pyr & $129-00-0$ \\
\hline Dibenzo $(a, h)$ anthraceen & Dibenzo(a,h)anthraceen & DBahAnt & $53-70-3$ \\
\hline Acenafteen & Acenafteen & AcNe & $83-32-9$ \\
\hline Fluoreen & Fluoreen & Fle & $86-73-7$ \\
\hline Hexachloorbenzeen & $\mathrm{HCB}$ & $\mathrm{HCB}$ & $118-74-1$ \\
\hline Hexachloorbutadieen & $\mathrm{HCBD}$ & HxClbtDen & $87-68-3$ \\
\hline Alfa-hexachloorcyclohexaan & $\mathrm{a}-\mathrm{HCH}$ & $\mathrm{aHCH}$ & $319-84-6$ \\
\hline Beta-hexachloorcyclohexaan & $\beta-\mathrm{HCH}$ & $\mathrm{bHCH}$ & $319-85-7$ \\
\hline Gamma-hexachloorcyclohexaan & $\mathrm{Y}-\mathrm{HCH}$ & $\mathrm{CHCH}$ & $58-89-9$ \\
\hline 4,4'-dichloordifenyltrichloorethaan & $\mathrm{p}, \mathrm{p}^{\prime}-\mathrm{DDT}$ & 44DDT & $50-29-3$ \\
\hline 4,4'-dichloordifenyldichloorethaan & $p, p^{\prime}-D D D$ & 44DDD & $72-54-8$ \\
\hline 4,4'-dichloordifenyltrichlooretheen & $p, p^{\prime}-D D E$ & 44DDE & $72-55-9$ \\
\hline Dieldrin & Dieldrin & dieldn & $60-57-1$ \\
\hline Heptachloor & Heptachloor & $\mathrm{HpCl}$ & $76-44-8$ \\
\hline Trans-heptachloorepoxide & b-HEPO & tHpClepO & $28044-83-9$ \\
\hline Pentachloorbenzeen & $\mathrm{QCB}$ & PeCIBen & $608-93-5$ \\
\hline 2,2,4'-trichloorbifenyl & PCB28 & PCB28 & $7012-37-5$ \\
\hline $2,4^{\prime}, 5$-trichloorbifenyl & PCB31 & PCB31 & $16606-02-3$ \\
\hline $2,2^{\prime}, 4,4^{\prime}$-tetrachoorbifenyl & PCB47 & PCB47 & $2437-79-8$ \\
\hline $2,2^{\prime}, 4,5^{\prime}$-tetrachoorbifenyl & PCB49 & PCB49 & $41464-40-8$ \\
\hline $2,2^{\prime}, 5,5^{\prime}$-tetrachoorbifenyl & PCB52 & PCB52 & $35693-99-3$ \\
\hline $2,3,3^{\prime}, 4^{\prime}$-tetrachoorbifenyl & PCB56 & PCB56 & $41464-43-1$ \\
\hline $2,2^{\prime}, 3,4,4^{\prime}$-pentachloorbifenyl & PCB85 & PCB85 & $65510-45-4$ \\
\hline $2,2^{\prime}, 3,4,5^{\prime}$-pentachloorbifenyl & PCB87 & PCB87 & $38380-02-8$ \\
\hline $2,2^{\prime}, 3,4^{\prime}, 5^{\prime}$-pentachloorbifenyl & PCB97 & PCB97 & $41464-51-1$ \\
\hline
\end{tabular}




\begin{tabular}{|c|c|c|c|}
\hline Component & Rapport & Donar-code & CAS-nummer \\
\hline $2,2^{\prime}, 4,5,5^{\prime}$-pentachloorbifenyl & PCB101 & PCB101 & $37680-73-2$ \\
\hline $2,2^{\prime}, 3,4,5,5^{\prime}$-hexachloorbifenyl & PCB105 & PCB105 & $32598-14-4$ \\
\hline $2,3,3^{\prime}, 4^{\prime}, 6$-pentachloorbifenyl & PCB110 & PCB110 & $38380-03-9$ \\
\hline $2,3^{\prime}, 4,4^{\prime}, 5$-pentachloorbifenyl & PCB118 & PCB118 & $31508-00-6$ \\
\hline Som PCB 128 en PCB 174 & PCB128+174 & S_PCB128174 & n.v.t. \\
\hline $2,2^{\prime}, 3,3^{\prime}, 4,4^{\prime}$-hexachloorbifenyl & PCB128 & PCB128 & $38380-07-3$ \\
\hline $2,2^{\prime}, 3,4,4^{\prime}, 5$-hexachloorbifenyl & PCB137 & PCB137 & 35694-06-5 \\
\hline $2,2^{\prime}, 3,4,4^{\prime}, 5^{\prime}$-hexachloorbifenyl & PCB138 & PCB138 & $35065-28-2$ \\
\hline $2,2^{\prime}, 3,4,5,5^{\prime}$-hexachloorbifenyl & PCB141 & PCB141 & $52712-04-6$ \\
\hline $2,2^{\prime}, 3,4^{\prime}, 5^{\prime}, 6$-hexachloorbifenyl & PCB149 & PCB149 & $38380-04-0$ \\
\hline $2,2^{\prime}, 3,5,5^{\prime}, 6$-hexachloorbifenyl & PCB151 & PCB151 & $52663-63-5$ \\
\hline $2,2^{\prime}, 4,4^{\prime}, 5,5^{\prime}$-hexachloorbifenyl & PCB153 & PCB153 & $35065-27-1$ \\
\hline Som PCB 156 en PCB 172 & PCB156+172 & S_PCB156172 & n.v.t. \\
\hline $2,3,3^{\prime}, 4,4^{\prime}, 5$-hexachloorbifenyl & PCB156 & PCB156 & $38380-08-4$ \\
\hline $2,2^{\prime}, 3,3^{\prime}, 4,4^{\prime}, 5$-heptachloorbifenyl & PCB170 & PCB170 & $35065-30-6$ \\
\hline $2,2^{\prime}, 3,4,4^{\prime}, 5,5^{\prime}$-heptachloorbifenyl & PCB180 & PCB180 & $35065-29-3$ \\
\hline $2,2^{\prime}, 3,3^{\prime}, 4,4^{\prime}, 5,5^{\prime}$-octachloorbifenyl & PCB194 & PCB194 & $35694-08-7$ \\
\hline $2,2^{\prime}, 3,3^{\prime}, 5,5^{\prime}, 6,6^{\prime}$-octachloorbifenyl & РCB202 & PCB202 & $2136-99-4$ \\
\hline $2,2^{\prime}, 3,3^{\prime}, 4,4^{\prime}, 5,5^{\prime}, 6$-nonachloorbifenyl & PCB206 & PCB206 & $40186-72-9$ \\
\hline $2,2^{\prime}, 3,4^{\prime}, 5,5^{\prime}, 6$-heptachloorbifenyl & PCB187 & PCB187 & $52663-68-0$ \\
\hline Dibutyltin (kation) & DBT kation & DC4ySn & $1002-53-5$ \\
\hline Tributyltin (kation) & TBT kation & TC4ySn & $688-73-3$ \\
\hline Trifenyltin (kation) & TPT kation & TFySn & $668-34-8$ \\
\hline Monobutyltin (kation) & MBT kation & MC4ySn & 78763-54-9 \\
\hline Monofenyltin (kation) & MPT kation & MFySn & $2406-68-0$ \\
\hline Difenyltin (kation) & DPT kation & DFySn & $1011-95-6$ \\
\hline 2,4,4'-tribroomdifenylether & BDE28 & PBDE28 & $41318-75-6$ \\
\hline 2,2',4,4'-tribroomdifenylether & BDE47 & PBDE47 & $5436-43-1$ \\
\hline $2,3^{\prime}, 4,4^{\prime}$-tetrabroomdifenylether & BDE66 & PBDE66 & $189084-61-5$ \\
\hline $2,2^{\prime}, 3,4,4^{\prime}$-pentabroomdifenylether & BDE85 & PBDE85 & $182346-21-0$ \\
\hline $2,2^{\prime} 4,4^{\prime}$-tetrabroomdifenylether & BDE99 & PBDE99 & $60348-60-9$ \\
\hline $2,2^{\prime}, 4,5^{\prime}$-tetrabroomdifenylether & BDE100 & PBDE100 & $189084-64-8$ \\
\hline 2,4,4',6-tetrabroomdifenylether & BDE153 & PBDE153 & $189084-63-7$ \\
\hline Som PBB153 en PBDE154 & BDE154+BB153 & SPBB153DE154 & n.v.t. \\
\hline $2,2^{\prime}, 4,4^{\prime}, 5,5^{\prime}$-hexabroombifenyl & BB153 & PBB153 & $59080-40-9$ \\
\hline $2,2^{\prime}, 4,4^{\prime}, 5,6^{\prime}$-hexabroomdifenylether & BDE154 & PBDE154 & $207122-15-4$ \\
\hline $2,2^{\prime}, 3,4,4^{\prime}, 5^{\prime}, 6$-heptabroomdifenylether & BDE183 & PBDE183 & $207122-16-5$ \\
\hline Hexabromocyclododecanen & $\mathrm{HBCD}$ & $\mathrm{HBCD}$ & 25637-99-4 \\
\hline Perfluor-n-butaanzuur & PFBA & PFBA & $375-22-4$ \\
\hline Perfluorbutaansulfonaat & PFBS & PFBS & $375-73-5$ \\
\hline Perfluordecaanzuur & PFDcA & PFDA & $335-76-2$ \\
\hline Perfluor-n-dodecaanzuur & PFDoA & PFDoA & $307-55-1$ \\
\hline Perfluordecaansulfonaat & PFDS & PFDS & $335-77-3$ \\
\hline Perfluor-n-heptaanzuur & PFHpA & PFHpA & $375-85-9$ \\
\hline Perfluorheptaansulfonaat & PFHpS & PFHpS & $375-92-8$ \\
\hline Perfluor-n-hexaanzuur & PFHXA & PFHXA & $307-24-4$ \\
\hline Perfluorhexaansulfonaat & PFHxS & PFHxS & $355-46-4$ \\
\hline Perfluor-n-nonaanzuur & PFNA & PFNA & $375-95-1$ \\
\hline Perfluoroctaanzuur & PFOA & PFOA & $335-67-1$ \\
\hline Perfluoroctaansulfonaat & PFOS & PFOS & 1763-23-1 \\
\hline Perfluor-n-pentaanzuur & PFPeA & PFPA & $2706-90-3$ \\
\hline Perfluortetradecaanzuur & PFTeA & PFTeDA & $376-06-7$ \\
\hline Perfluortridecaanzuur & PFTrA & PFTDA & 72629-94-8 \\
\hline Perfluorundecaanzuur & PFUnA & PFUdA & $2058-94-8$ \\
\hline
\end{tabular}




\subsubsection{PCB's en OCP's}

De monsters worden opgewerkt door middel van een Soxhlet-extractie die simultaan is voor de verschillende halogeenverbindingen. De halogeenverbindingen worden uit de vetfractie geïsoleerd door een tweevoudige kolomchromatografische scheiding, waarna analyse plaatsvindt met behulp van gaschromatografie. De monsters worden gemeten tegen een kalibratiecurve en gedetecteerd met GCECD.

De methode is vastgelegd in Wageningen Marine Research ISW 2.10.3.001 “Dierlijk weefsel. Bepalen van het gehalte aan polychloorbifenylen (PCB) na extractie; (GC-ECD) en "Dierlijk weefsel. Bepalen van het gehalte aanorganochloorbestrijdingsmiddelen (OCP) na extractie; GC-ECD" en staat op de scope van de Raad voor Accreditatie onder testlaboratoriumnummer L097, verrichting nummer 10 voor de PCB en 12 voor de OCP.

Recent is er voor de meting overgestapt van een 2 koloms systeem naar een systeem met één HT-8 kolom. Aangezien PCB128 een mogelijke overlap heeft met PCB174 en PCB156 een mogelijke overlap heeft met PCB172 op de HT-8 kolom en dit momenteel nog niet voldoende gevalideerd is, worden de som PCB128+174 en de som PCB156+172 gerapporteerd zonder Q als indicatieve waarden.

\subsubsection{PBDE's en HBCD}

Het analysemonster wordt gehomogeniseerd en het vocht wordt met natriumsulfaat verwijderd. De gebromeerde vlamvertragers worden met behulp van een Soxhlet extractie met pentaan/dichloormethaan opgelost. Het extract wordt met zwavelzuur behandeld om eventuele verontreinigingen en vet te verwijderen. Zeer vuile monsters kunnen verder worden gezuiverd met behulp van gel permeatie chromatografie (GPC). Hierna wordt het extract verder gezuiverd met behulp van silicagelkolommen. De uiteindelijke bepaling wordt uitgevoerd met capillaire gaschromatografie en massa selectieve detectie.

De methode is vastgelegd in Wageningen Marine Research ISW 2.10.3.017 "Dierlijk weefsel. Bepalen van het gehalte aan gebromeerde vlamvertragers na extractie; GC-NCl-MS" en staat op de scope van de Raad voor Accreditatie onder testlaboratoriumnummer L097, verrichting nummer 8. Aangezien PBDE154 een overlap heeft met BB153, wordt de som van beide componenten gerapporteerd.

\subsubsection{Kwik}

Voor de bepaling wordt het monster gedroogd en verast in een oven om kwik vrij te maken uit het monster. De vrijgekomen verbindingen worden d.m.v. zuurstof naar een catalyst tube geleid, waar oxidatie plaatsvindt en halogenen en stikstof- en zwaveloxiden worden verwijderd. De overige ontledingsproducten worden d.m.v. zuurstof naar een amalgamator geleid, waar de kwikverbindingen worden omgezet in metallisch kwik. Het gehalte aan kwik wordt vervolgens d.m.v. vlamloze atoomabsorptie spectrometrie bepaald. De monsters worden gemeten tegen een kalibratiecurve, die gemaakt is door het meten van verschillende hoeveelheden van een gecertificeerd referentiemateriaal. De methode is vastgelegd in Wageningen Marine Research ISW 2.10.3.025 "Dierlijk weefsel. Bepalen van het gehalte aan kwik m.b.v. SMS100 mercury analyser; vlamloze AAS" en staat op de scope van de Raad voor Accreditatie onder testlaboratoriumnummer L097, verrichting nummer 6. 


\subsubsection{Koper, cadmium, lood, zink, chroom, arseen, nikkel}

Deze analyses werden uitbesteed aan TNO Triskelion. Een deel van het monster wordt in duplo ontsloten met salpeterzuur en waterstofperoxide, volgens TNO Triskelion voorschrift TRIS/LSP/108. In de verkregen oplossing wordt het gehalte aan arseen, cadmium, chroom, koper, lood, nikkel en zink bepaald m.b.v. ICP-MS, volgens voorschrift TRIS/LSP/055 en TRIS/LSP/108. De kwantificering vindt plaats aan de hand van externe kalibratiestandaarden en om te corrigeren voor fluctuaties in de apparatuur wordt gebruik gemaakt van een interne standaard (rhodium).

TNO Triskelion is geaccrediteerd door de Raad voor Accreditatie voor genoemde metalen (testlaboratoriumnummer L546, verrichting nummer 30), behalve voor nikkel. Nikkel kan momenteel niet met het kwaliteitskenmerk $\mathrm{Q}$ worden gerapporteerd.

\subsubsection{PAK's}

De PAK's worden vrijgemaakt uit het monster door dit te schudden met warme ethanolische kaliumhydroxide. Na extraheren met hexaan wordt het verkregen extract gezuiverd over een silicagelaluminiumoxide-kolom. Van het gezuiverde extract wordt hexaan afgedampt onder toevoeging van acetonitril. De PAK's, in acetonitril, worden in een hogedrukvloeistofchromatograaf gescheiden en gedetecteerd door een fluorescentiemeter.

De methode is vastgelegd in Wageningen Marine Research ISW 2.10.3.005 "Schaal- en Schelpdieren. Bepalen van het gehalte aan polycyclische aromatische koolwaterstoffen (PAK) na extractie; HPLC met fluorescentiedetectie" en staat op de scope van de Raad voor Accreditatie onder testlaboratoriumnummer L097, verrichting nummer 15.

De componenten dibenzo(ah)antraceen en indeno(1,2,3-cd)pyreen kunnen momenteel niet met het kwaliteitskenmerk Q worden gerapporteerd.

\subsubsection{Droge stof/as}

Voor de bepaling van het droge stofgehalte wordt het gewogen monster gemengd met een oppervlakte vergrotende stof, vervolgens gedroogd in een stoof $\left(105^{\circ} \mathrm{C}, 3\right.$ uur) en na afkoelen in een exsiccator teruggewogen.

De methode is vastgelegd in Wageningen Marine Research ISW 2.10.3.011 "Dierlijk weefsel. Bepalen van het gehalte aan vocht; gravimetrie" staat op de scope van de Raad voor Accreditatie onder testlaboratoriumnummer L097, verrichting nummer 2.

Voor de asbepaling wordt het monster langzaam verwarmd en gedroogd in een kroes op een kookplaat. Daarna wordt het monster gedurende 22 uur verast in een moffeloven bij een temperatuur van $550 \pm 15^{\circ} \mathrm{C}$. Na afkoelen in een exsiccator wordt het monster teruggewogen.

De methode is vastgelegd in Wageningen Marine Research ISW 2.10.3.018 "Dierlijk weefsel. Bepalen van het gehalte aan as; gravimetrie" en staat op de scope van de Raad voor Accreditatie onder testlaboratoriumnummer L097, verrichting nummer 4.

Het percentage asvrijdrooggewicht wordt berekend uit het gehalte droge stof en as.

\subsubsection{Vet}

De totaal vet bepaling geschiedt volgens een aangepaste versie van de Bligh en Dyer methode, gebaseerd op een koude chloroform-methanol extractie.

De methode is vastgelegd in Wageningen Marine Research ISW 2.10.3.002 "Dierlijk weefsel. Bepalen van het gehalte aan vet volgens Bligh and Dyer; gravimetrie" en staat op de scope van de Raad voor Accreditatie onder testlaboratoriumnummer L097, verrichting nummer 1.

De bepaling van vrij extraheerbaar vet wordt uitgevoerd als onderdeel van de PCB analyse. Na de Soxhlet extractie wordt een deel van het extract drooggedampt en het residu gewogen. De bepaling van vrij extraheerbaar vet staat niet op de scope van de Raad voor Accreditatie. 


\subsubsection{Organotinverbindingen}

Zes organotinverbindingen worden gerapporteerd (MBT, DBT, TBT, MPT, DPT en TPT) als tinverbinding en als kation.

Ionogene organotinverbindingen komen via een schudextractie met methanol, azijnzuur en hexaan beschikbaar voor alkylering. Vervolgens worden de alkyltinverbindingen geëthyleerd met natriumtetraethylboraat. Na een clean-up met aluminiumoxide worden de extracten geanalyseerd met behulp van GC-MS (SIM mode).

De methode is vastgelegd in Wageningen Marine Research ISW 2.10.3.024 "Dierlijk weefsel. Bepalen van het gehalte aan organotinverbindingen na extractie en derivatisatie; GC-EI-MS" en staat op de scope van de Raad van Accreditatie onder testlaboratoriumnummer L097, verrichting nummer 18.

\subsubsection{Perfluorverbindingen}

De analyse van perfluorverbindingen in de monsters wordt als volgt uitgevoerd (Kwadijk, C. et al., 2010): Na homogeniseren wordt 1-5 gram monster genomen en geëxtraheerd door middel van ultrasone extractie met acetonitril. Vervolgens worden de extracten gedroogd over een glasfilter met natriumsulfaat waarna er een opschoningsstap met actieve kool plaatsvindt. Het eindextract wordt geanalyseerd met behulp van LC-MS-ESI.

De methode is vastgelegd in Wageningen Marine Research ISW 2.10.3.045 "Dierlijk weefsel: Bepalen van het gehalte aan perfluorverbindingen na extractie; HPLC-ESI-MS" en staat op de scope van de Raad voor Accreditatie onder testlaboratoriumnummer L097, verrichting nummer 16.

\subsection{Dataopslag en -registratie}

De analyseresultaten die in LIMS worden opgeslagen, worden gecontroleerd door een andere analist, bevoegd is voor de uitvoering van betreffende bepaling, dan de uitvoerend analist. Een DONAR-script is beschikbaar dat ervoor zorgt dat de gegevens uit LIMS op de juiste manier in een DONAR-file terecht komen. De Exceltabellen die uit LIMS worden gegenereerd en in het rapport worden opgenomen, worden door de uitvoerende analisten gecontroleerd op eventuele fouten en geparafeerd voor vrijgave. Van elk analyseresultaat wordt beoordeeld of het voldoet aan de kwaliteitscriteria die worden genoemd in het betreffende ISW, indien dit niet het geval is wordt de reden daarvan in het rapport vermeld. 


\section{Resultaten}

De resultaten vermeld in dit rapport zijn alleen van toepassing op de geanalyseerde monsters. De chemische analyses zijn uitgevoerd in het laboratorium locatie IJmuiden in de periode van november $2016 \mathrm{t} / \mathrm{m}$ februari 2017.

De verzamelde gegevens en analyse-uitkomsten zijn in tabelvorm weergegeven in de bijlagen van dit rapport en zullen volgens opdracht tevens als Excel spreadsheet elektronisch worden verzonden. De analyse-uitkomsten en bijbehorende biologische gegevens van de mosselen en de oesters zullen ook worden aangeleverd als DIF voor opslag in DONAR.

De tabellen zijn als volgt gepresenteerd op aparte, volgens onderwerp gescheiden, bijlagen:

\begin{tabular}{|c|l|}
\hline Bijlage & Titel \\
\hline 1 & Biologische parameters oesters Eems-Dollard BOCHTVWTM en mosselen Westerschelde KNUITHK \\
\hline 2 & Gehalten PCB's in mosselen en oesters \\
\hline 3 & Gehalten metalen in mosselen en oesters \\
\hline 4 & Gehalten PAK's in mosselen en oesters \\
\hline 5 & Gehalten OCP's en PBDE's in mosselen en oesters \\
\hline 6 & Gehalten organotinverbindingen mosselen en oesters \\
\hline 7 & Gehalten perfluorverbindingen mosselen en oesters \\
\hline 8.1 & Validatiegegevens analysemethoden, resultaten referentiematerialen \\
\hline 8.2 & Validatiegegevens analysemethoden, resultaten ringonderzoek Quasimeme in biota \\
\hline 8.3 & Validatiegegevens analysemethoden, rapportagegrenzen en meetonzekerheid \\
\hline
\end{tabular}

T.a.v. de resultaten van Wageningen Marine Research kan opgemerkt worden dat ze voldoen aan de kwaliteitseisen, zoals genoemd in 3.3 kwaliteitsborging Wageningen Marine Research. Er zijn geen afwijkingen van de kwaliteitscriteria geconstateerd, zoals gesteld in de geaccrediteerde werkvoorschriften, behalve voor de geaccrediteerde componenten $\mathrm{HCB}, \mathrm{y}-\mathrm{HCH}$, dibenzo(ah)antraceen en indeno(1,2,3-cd)pyreen. Deze geaccrediteerde componenten mogen daarom niet met het kwaliteitskenmerk Q worden gerapporteerd en zijn als indicatieve waarden (kwaliteitswaardecode 4) opgegeven om de volgende redenen:

- $\mathrm{HCB}$ en $\mathrm{y}-\mathrm{HCH}$ :

De oestermonsters uit de bocht van Watum, 2016/3420 2016/3421 worden indicatief gerapporteerd voor HCB. Dit geldt ook voor $\mathrm{y}-\mathrm{HCH}$ in de mosselmonsters uit de Westerschelde, Knuitershoek (LIMS nummers 2016/3412 t/m 2016/3415). De blanco voldoet hierdoor niet aan aan de gestelde eisen voor deze twee componenten, dit omdat de waarde gevonden in de blanco groter is dan $15 \%$ van de gevonden waarde in het monster.

- dibenzo(ah)antraceen en indeno(1,2,3-cd)pyreen:

Voor de componenten dibenzo(ah)antraceen en indeno(1,2,3-cd)pyreen worden regelmatig zscores $>|3|$ behaald in ringonderzoeken, zodat de resultaten niet als volledig betrouwbaar gerapporteerd kunnen worden (onbeheerste kwaliteit).

De resultaten van de IRM's, gemeten door Wageningen Marine Research, zijn gecontroleerd met betrekking tot overschrijdingen van de 2s- en 3s-grenzen van de door Wageningen Marine Research intern gehanteerde kwaliteitscontrolekaarten voor de betreffende elementen. Dit is weergegeven in bijlage 8.1. Indien de 3s-grens wordt overschreden wordt daarop, vastgelegd in ons kwaliteitssysteem, adequaat actie ondernomen. Bijlage 8.1 toont dat aan de metingen in de IRM's, in 2016 uitgevoerd door Wageningen Marine Research, de kwalificatie goed kan worden toegekend. 
In bijlage 8.2 zijn de resultaten van deelname aan Quasimeme ringonderzoeken weergegeven. Indien een z-score de kwalificatie 'unsatisfactory' heeft gekregen wordt daarop, vastgelegd in ons kwaliteitssysteem, adequaat actie ondernomen. Hierop vindt jaarlijks controle plaats door de Raad voor Accreditatie.

De betekenissen van de kwalificaties, zoals door Quasimeme toegekend, zijn als volgt:

Satisfactory: $\quad|Z|<2$, resultaat voldoet

Unsatisfactory: $\quad|Z|>3$, resultaat voldoet niet (adequate actie vereist)

Questionable: $\quad|Z|<3$, resultaat is twijfelachtig (geen actie vereist)

Consistent: $\quad$ er is een waarde $(x)<$ rapportagegrens door het deelnemend lab gerapporteerd, deze waarde was in overeenstemming met de assigned value (consensus waarde), bv. $<0.03$ gerapporteerd, terwijl assigned value 0.02 is

Inconsistent: er is een waarde $(x)<$ rapportagegrens door het deelnemend lab gerapporteerd, deze waarde was niet in overeenstemming met de assigned value (consensus waarde), bv. $<0.03$ gerapporteerd, terwijl assigned value 0.06 is

Blanc: geen z-score bepaald door Quasimeme (mogelijke oorzaken: te weinig laboratoria hebben resultaten gerapporteerd of de spreiding van de resultaten tussen de laboratoria onderling was te groot)

In 2016 is aan twee ringonderzoekrondes van Quasimeme deelgenomen (de labcode van Wageningen Marine Research is Q127).

Bijlage 8.2 toont dat 3 keer de kwalificatie unsatisfactory is toegekend in het jaar 2016, betreffende de componenten benzo(a)pyreen, dibenz(ah)antraceen en indeno(123)peryleen.

De ringonderzoeken zijn binnen ons kwaliteitssysteem geëvalueerd en waar nodig zijn passende maatregelen genomen. Van genoemde componenten zijn alleen diegene die daar aanleiding toe gaven gerapporteerd met kwaliteitswaardecode 4.

T.a.v. de toetsingscriteria op de resultaten van TNO Triskelion kan het volgende gezegd worden: Wageningen Marine Research hanteert een maximum toelaatbare rsd van $15 \%$ voor metalen tussen de duplowaarden van een monster, geanalyseerd door TNO Triskelion. De resultaten van het oude IRM van WMR, gemeten door TNO Triskelion, voldoen niet aan de gestelde eisen. De duplo verschillen zijn te hoog voor koper en lood. Ook bij heranalyse van het IRM werden te hoge duplowaarden vastgesteld. Dit criterium voor duploverschillen werd dit jaar voor geen enkel schelpdiermonster overschreden.

Ook voldoen de analyses aan de gestelde eisen van het Triskelion kwaliteitssysteem, TNO Triskelion heeft alle resultaten van de metaalanalyses onder Q (ISO 17025 accreditatie) gerapporteerd met uitzondering van nikkel. De analyses worden daarom onder Q gerapporteerd in dit rapport.

TNO Triskelion neemt niet deel aan de ringonderzoeken van Quasimeme, de kwaliteit van hun analyses wordt echter wel geborgd door deelname aan andere ringonderzoeken, nl. die van FAPAS en IRMM.

In bijlage 8.3 zijn de rapportagegrenzen en meetonzekerheden weergegeven.

De rapportagegrenzen voor de anorganische componenten en voor de metalen zijn vaste rapportagegrenzen die zijn vastgesteld uit de historie van de blancobepalingen.

De rapportagegrenzen voor de organische componenten worden vastgesteld aan de hand van de laagst gemeten standaard.

De rapportagegrens is afhankelijk van de hoeveelheid ingewogen monster en is dus eigenlijk voor ieder monster verschillend, de compromis rapportagegrenzen zijn in bijlage 7.3 weergegeven.

De RMS (root mean square) wordt berekend volgens NEN 7779 als basis voor de gecombineerde meetonzekerheid (standard uncertainty) uit de resultaten van verschillende ringonderzoeken (verschillende matrices) van meerdere rondes $(n>8)$. De relatieve uitgebreide meetonzekerheid (expanded uncertainty) is gedefinieerd als twee maal de relatieve standard uncertainty. De relatieve standard uncertainty is weergegeven in bijlage 8.3. Hierin zijn de reproduceerbaarheid, de tussenmonster-spreiding en de methode juistheid verwerkt. Eventuele inhomogeniteit van het monster is hier niet in verwerkt, maar is bij ringonderzoekmonsters niet van toepassing.

Voor de rapportage aan OSPAR dient bij iedere meetwaarde de expanded uncertainty (95\% betrouwbaarheidsinterval) berekend te worden. De expanded uncertainty is gedefinieerd als tweemaal 
de standaard deviatie. Voor OSPAR dient dus een absolute meetonzekerheid gerapporteerd te worden. De berekening van de absolute expanded uncertainty is gebaseerd op onderstaande formules uit de OSPAR guideline voor de bepaling van de meetonzekerheid. De relative standard uncertainty (uitgedrukt in \%) wordt door Wageningen Marine Research als maat voor de $\mathrm{v}_{c}$ gehanteerd. In bijlage 8.3 zijn zowel de relative standard uncertainty $\left(=v_{c}\right)$ als de constant error $\left(=d_{c}\right)$ opgenomen. Beide dienen als input in de formules voor de berekening van de absolute expanded uncertainty.

Formules uit de OSPAR quideline:

$s_{C}=\sqrt{d_{C}^{2}+\left(\frac{v_{c}}{100}\right)^{2} C^{2}}$

waarin:

$\mathrm{S}_{\mathrm{c}}=$ standard deviation (eenheid = eenheid van concentratie component)

$\mathrm{d}_{\mathrm{c}}=$ "combined constant error" (eenheid = eenheid van concentratie component)

$\mathrm{V}_{\mathrm{c}}=$ variatie coëfficiënt (eenheid= percentage)

$\mathrm{C}=$ concentratie van de component in het monster (meetwaarde)

$U_{C}=2 s_{C}$

waarin:

$\mathrm{U}_{\mathrm{c}}=$ (absolute) expanded uncertainty (eenheid = eenheid van concentratie component)

Voor componenten waarvoor geen deelname plaatsvindt aan ringonderzoeken is, indien mogelijk, de meetonzekerheid vastgesteld op basis van juistheidsbepaling en monsterinhomogeniteit. Voor componenten waarvoor zowel geen ringonderzoeken als geen referentiematerialen voorhanden zijn, kan de meetonzekerheid niet worden vastgesteld. Voor componenten waarvoor het aantal deelgenomen rondes aan ringonderzoeken minder bedraagt dan 8, kan nog geen meetonzekerheid worden vastgesteld volgens NEN 7779. 


\section{Aanbevelingen}

Indien, vanwege het verdringen van de Blauwe mossel door de Japanse oester in de onderzoeksgebieden, geheel overgestapt moet worden op de bemonstering van oesters zou een trendbreuk op kunnen treden. Daarom is geadviseerd om, indien mogelijk, een paar jaar beide soorten naast elkaar te bemonsteren om een vergelijking tussen beide soorten te kunnen maken. Dit jaar kon echter wederom geen vergelijking worden gemaakt tussen mosselen en oesters door het ontbreken van mosselen afkomstig van de Eems-Dollard. De resultaten van de Westerschelde suggereren dat voor bepaalde stoffen (koper en zink met name) een trendbreuk op zal treden bij het overstappen van mosselen op oesters. Daarnaast geldt wel dat de toekomst van de Japanse oesters in Nederland door de oesterboorder (Japanse stekelboorder, Ocenebra inornata) ook niet gegarandeerd wordt (zie IMARES nieuwsbrief van 27 oktober 2015 (Bolman 2015)).

Aanbevolen wordt, om in het kader van de Kaderrichtlijn Marien (KRM), die componenten aan het monitoringprogramma toe te voegen waarvoor een Milieukwaliteitsnorm (MKN) in biota is vastgesteld (zie richtlijn 2011/0429 (COD), 31/01/2012. Voorstel voor een RICHTLIJN VAN HET EUROPEES PARLEMENT EN DE RAAD tot wijziging van Richtlijnen 2000/60/EG en 2008/105/EG betreffende prioritaire stoffen op het gebied van het waterbeleid).

Geadviseerd wordt de stoffen a-HEPO en dicofol in het meetprogramma op te nemen, aangezien een EQS (Environmental Quality Standard) voor deze stof in biota is vastgesteld die wordt vermeld in Richtlijn 2013/39/EU van 12 augustus 2013 tot wijziging van Richtlijn 2000/60/EG en Richtlijn 2008/105/EG wat betreft prioritaire stoffen op het gebied van waterbeleid. Genoemde richtlijn is gepubliceerd in het EU-Publicatieblad en wordt rechtsgeldig vanaf 2018. Uiterlijk dan moeten de stoffen uit deze richtlijn worden gemonitord, maar het is aan te bevelen nu al inzicht te krijgen in de gehalten van deze stoffen. 


\section{$6 \quad$ Literatuur}

Application note van SGE Analytical Science: "HT8: The perfect PCB column"

Bolman B.C. 2015, IMARES nieuwsbrief "Oesterboorder bedreigt Nederlandse oestersector" link: http://www.wageningenur.nl/nl/Expertises-

Dienstverlening/Onderzoeksinstituten/LEI/show/Oesterboorder-bedreigt-Nederlandseoestersector.htm?utm_source=Measuremail\&utm_medium=email\&utm_campaign=Kust+en+Zee, 27 oktober 2015

Weijden, M. van der 2015. "Monitoring chemische stoffen in mariene schelpdieren 2015, meetplan chemisch meetnet MWTL", 15 april 2015. 


\section{$7 \quad$ Kwaliteitsborging}

Het chemisch laboratorium te IJmuiden beschikt over een NEN-EN-ISO/IEC 17025:2005 accreditatie voor testlaboratoria met nummer L097. Deze accreditatie is geldig tot 1 april 2021 en is voor het eerst verleend op 27 maart 1997; deze accreditatie is verleend door de Raad voor Accreditatie. Het chemisch laboratorium heeft hierdoor aangetoond in staat te zijn op technisch bekwame wijze valide resultaten te leveren en te werken volgens de ISO17025 norm. De scope (L097) met de geaccrediteerde analysemethoden is te vinden op de website van de Raad voor Accreditatie (www.rva.nl).

Op grond van deze accreditatie is het kwaliteitskenmerk $\mathrm{Q}$ toegekend aan resultaten van componenten die op de scope zijn vermeld, mits aan alle kwaliteitseisen is voldaan. Het kwaliteitskenmerk $\mathrm{Q}$ staat vermeld in de tabellen met de onderzoeksresultaten. Indien het kwaliteitskenmerk $Q$ niet staat vermeld is de reden hiervan vermeld.

De kwaliteit van de analysemethoden wordt op verschillende manieren gewaarborgd:

- $\quad$ Bij iedere meetserie wordt een eerstelijnscontrole uitgevoerd: de resultaten van elke (serie van) meting(en) worden gecontroleerd door het gebruik van gecertificeerd en/of intern referentiemateriaal. Deze gegevens worden in kwaliteitscontrolekaarten bijgehouden. De "gecertificeerde" gehalten en de waarden van de waarschuwingsgrens (tweemaal standaarddeviatie) van de gebruikte referentiematerialen zijn weergegeven in bijlage 8.1.

- De juistheid van de analysemethoden wordt regelmatig getoetst door deelname aan ringonderzoeken waaronder die georganiseerd door QUASIMEME (derdelijnscontrole). Resultaten van de rondes zijn weergegeven in bijlage 8.2. Indien geen ringonderzoek voorhanden is, wordt een tweedelijnscontrole (blind monster) uitgevoerd.

- $\quad$ Naast de lijnscontroles worden de volgende algemene kwaliteitscontroles uitgevoerd:

- Blanco onderzoek

- $\quad$ Terugvinding (recovery)

- Interne standaard voor borging opwerkmethode

- Injectie standaard

- $\quad$ Gevoeligheid

Alle controles staan beschreven in Wageningen Marine Research ISW 2.10.2.105.

Indien sprake is van onbeheerste kwaliteit worden passende maatregelen genomen waarop jaarlijks controle plaatsvindt door de RvA.

Op speciaal verzoek van RWS zijn ook rapportagegrenzen en meetonzekerheden per component gerapporteerd. Deze zijn weergegeven in bijlage 8.3.

Daarnaast beschikt Wageningen Marine Research over een ISO 9001:2008 gecertificeerd kwaliteitsmanagementsysteem (certificaatnummer: 187378-2015-AQ-NLD-RvA). Dit certificaat is geldig tot 15 september 2018. De organisatie is gecertificeerd sinds 27 februari 2001. De certificering is uitgevoerd door DNV Certification B.V.

TNO Triskelion te Zeist

Het TNO laboratorium beschikt over een geldig ISO/IEC 17025 certificaat voor testlaboratoria met nummer L546 en is geaccrediteerd voor de bepaling van de te analyseren metalen arseen, cadmium, chroom, koper, lood en zink in vismatrix. De scoop is te vinden op de website van de Raad voor Accreditatie www.rva.nl en is geldig tot 1 november 2020.

Om de kwaliteit van de analysen te waarborgen en eventuele trendbreuk met metingen van voorgaande jaren inzichtelijk te maken is door Wageningen Marine Research een intern referentiemateriaal (IRM) meegestuurd. 


\section{Verantwoording}

Rapport C029/17

Projectnummer: 4316100054

Dit rapport is met grote zorgvuldigheid tot stand gekomen. De wetenschappelijke kwaliteit is intern getoetst door een collega-onderzoeker en het verantwoordelijk lid van het managementteam van Wageningen Marine Research

Akkoord:

Dr. M Kotterman

Onderzoeker

Handtekening:

Datum:

24-07-2017

Akkoord:

Dr. ir. T.P. Bult

Director

Handtekening:

Datum:

24-07-2017 
BIJLAGE $1 \mathrm{t} / \mathrm{m} 8.3$ 
Bijlage 1: Biologische parameters oesters Eems-Dollard BOCHTVWTM en mosselen Westerschelde KNUITHK

\begin{tabular}{|c|c|c|c|c|c|c|c|c|}
\hline & & & & Aantal & $\begin{array}{c}\text { Gem. Gew schelp } \\
\mathrm{g}\end{array}$ & $\begin{array}{c}\text { Gem. gew vlees } \\
\mathrm{g}\end{array}$ & $\begin{array}{c}\text { Gem lengte } \\
\mathrm{mm}\end{array}$ & $\begin{array}{c}\text { Stdev lengte schelp } \\
\mathrm{mm}\end{array}$ \\
\hline RQ20161128/088 & Eems-Dollard: Bocht van Watum & $2016 / 3417$ & Oesters & 25 & 82.17 & 25.43 & 118.4 & 15.3 \\
\hline RQ20161128/088 & Eems-Dollard: Bocht van Watum & $2016 / 3418$ & Oesters & 25 & 69.91 & 20.91 & 110.7 & 21.6 \\
\hline RQ20161128/088 & Eems-Dollard: Bocht van Watum & $2016 / 3419$ & Oesters & 25 & 88.32 & 30.03 & 121.6 & 19.2 \\
\hline
\end{tabular}

\begin{tabular}{|c|c|c|c|c|c|c|c|c|}
\hline & & & & Aantal & $\begin{array}{c}\text { Gem. Gew schelp } \\
\mathrm{g}\end{array}$ & $\begin{array}{c}\text { Gem. gew vlees } \\
\text { g }\end{array}$ & $\begin{array}{c}\text { Gem lengte } \\
\mathrm{mm}\end{array}$ & $\begin{array}{l}\text { Stdev lengte schelp } \\
\mathrm{mm}\end{array}$ \\
\hline RQ20161128/089 & Westerschelde: Knuitershoek & $2016 / 3423$ & Oesters & 25 & 58.58 & 14.15 & 83.4 & 10.8 \\
\hline RQ20161128/089 & Westerschelde: Knuitershoek & $2016 / 3424$ & Oesters & 25 & 59.85 & 14.74 & 83.4 & 11.1 \\
\hline RQ20161128/089 & Westerschelde: Knuitershoek & $2016 / 3425$ & Oesters & 25 & 50.11 & 13.14 & 78.0 & 9.4 \\
\hline
\end{tabular}

\begin{tabular}{|c|c|c|c|c|c|c|c|c|}
\hline & & & & Aantal & $\begin{array}{c}\text { Gem. Gew schelp } \\
\mathrm{g}\end{array}$ & $\begin{array}{c}\text { Gem. gew vlees } \\
\text { g }\end{array}$ & $\begin{array}{c}\text { Gem lengte } \\
\mathrm{mm}\end{array}$ & $\begin{array}{l}\text { Stdev lengte schelp } \\
\mathrm{mm}\end{array}$ \\
\hline RQ20161128/087 & Westerschelde: Knuitershoek & $2016 / 3407$ & Mosselen & 703 & 2.47 & 0.54 & 27.9 & 1.8 \\
\hline RQ20161128/087 & Westerschelde: Knuitershoek & $2016 / 3408$ & Mosselen & 393 & 3.29 & 1.07 & 34.5 & 1.8 \\
\hline RQ20161128/087 & Westerschelde: Knuitershoek & $2016 / 3409$ & Mosselen & 224 & 5.29 & 1.63 & 41.0 & 1.9 \\
\hline RQ20161128/087 & Westerschelde: Knuitershoek & $2016 / 3410$ & Mosselen & 46 & 8.95 & 2.77 & 50.0 & 1.5 \\
\hline RQ20161128/087 & Westerschelde: Knuitershoek & $2016 / 3411$ & Mosselen & $\mathrm{nb}$ & $\mathrm{nb}$ & $\mathrm{nb}$ & $\mathrm{nb}$ & $\mathrm{nb}$ \\
\hline
\end{tabular}

$\mathrm{nb}=$ niet bepaald 


\begin{tabular}{|c|c|c|c|c|c|c|c|c|c|c|c|c|c|c|c|c|c|}
\hline & & & & $\begin{array}{c}\mathrm{CB}-28 \\
\mu \mathrm{g} / \mathrm{kg} \\
\mathrm{Q}\end{array}$ & $\begin{array}{c}\text { CB-31 } \\
\mu \mathrm{g} / \mathrm{kg} \\
\mathrm{Q}\end{array}$ & $\begin{array}{c}\mathrm{CB}-47 \\
\mu \mathrm{g} / \mathrm{kg} \\
\mathrm{Q}\end{array}$ & $\begin{array}{c}\mathrm{CB}-49 \\
\mu \mathrm{g} / \mathrm{kg} \\
\mathrm{Q}\end{array}$ & $\begin{array}{c}C B-52 \\
\mu g / k g \\
Q\end{array}$ & $\begin{array}{c}\text { CB-56 } \\
\mu g / k g \\
Q\end{array}$ & $\begin{array}{c}\text { CB-85 } \\
\mu \mathrm{g} / \mathrm{kg} \\
\mathrm{Q}\end{array}$ & $\begin{array}{c}\text { CB-87 } \\
\mu g / k g \\
Q\end{array}$ & $\begin{array}{c}\text { CB- } 97 \\
\mu g / k g \\
Q\end{array}$ & $\begin{array}{c}\text { CB-101 } \\
\mu \mathrm{g} / \mathrm{kg} \\
\mathrm{Q}\end{array}$ & $\begin{array}{c}\text { CB-105 } \\
\mu \mathrm{g} / \mathrm{kg} \\
\mathrm{Q}\end{array}$ & $\begin{array}{c}\text { CB-110 } \\
\mu \mathrm{g} / \mathrm{kg} \\
\mathrm{Q}\end{array}$ & $\begin{array}{c}\text { CB-118 } \\
\mu \mathrm{g} / \mathrm{kg} \\
\mathrm{Q}\end{array}$ & $\begin{array}{c}\text { CB- } 128+174 \\
\mu \mathrm{g} / \mathrm{kg} \\
\mathrm{Q}\end{array}$ \\
\hline RQ20161128/088 & $2016 / 3420$ & Oesters & Eems-Dollard: Bocht van Watum & 0.06 & 0.04 & 0.06 & 0.08 & 0.1 & 0.3 & 0.04 & 0.06 & 0.09 & 0.4 & 0.06 & 0.3 & 0.3 & 0.1 \\
\hline RQ20161128/088 & $2016 / 3421$ & Oesters & Eems-Dollard: Bocht van Watum & 0.07 & 0.04 & 0.07 & 0.09 & 0.1 & 0.3 & 0.05 & 0.07 & 0.1 & 0.5 & 0.07 & 0.4 & 0.3 & 0.1 \\
\hline RQ20161128/088 & $2016 / 3422$ & Oesters & Eems-Dollard: Bocht van Watum & 0.05 & 0.03 & 0.05 & 0.06 & 0.09 & 0.2 & 0.03 & 0.05 & 0.07 & 0.3 & 0.05 & 0.2 & 0.2 & 0.09 \\
\hline
\end{tabular}

\begin{tabular}{|c|c|c|c|c|c|c|c|c|c|c|c|c|c|c|c|c|c|c|}
\hline & & & & $\begin{array}{c}\text { CB-137 } \\
\mu \mathrm{g} / \mathrm{kg} \\
\mathrm{Q}\end{array}$ & $\begin{array}{c}C B-141 \\
\mu g / k g \\
Q\end{array}$ & $\begin{array}{c}\text { CB-149 } \\
\mu \mathrm{g} / \mathrm{kg} \\
\mathrm{Q}\end{array}$ & $\begin{array}{c}\text { CB-151 } \\
\mu \mathrm{g} / \mathrm{kg} \\
\mathrm{Q}\end{array}$ & $\begin{array}{c}\text { CB-153 } \\
\mu \mathrm{g} / \mathrm{kg} \\
\mathrm{Q}\end{array}$ & $\begin{array}{c}\text { CB-170 } \\
\mu \mathrm{g} / \mathrm{kg} \\
\mathrm{Q}\end{array}$ & $\begin{array}{c}\text { CB-180 } \\
\mu \mathrm{g} / \mathrm{kg} \\
\mathrm{Q}\end{array}$ & $\begin{array}{c}\text { CB-187 } \\
\mu \mathrm{g} / \mathrm{kg} \\
\mathrm{Q}\end{array}$ & $\begin{array}{c}\mathrm{CB}-194 \\
\mu \mathrm{g} / \mathrm{kg} \\
\mathrm{Q}\end{array}$ & $\begin{array}{c}\text { CB-202 } \\
\mu \mathrm{g} / \mathrm{kg} \\
\mathrm{Q}\end{array}$ & $\begin{array}{c}C B-206 \\
\mu g / k g \\
Q\end{array}$ & $\begin{array}{c}\text { CB-138 } \\
\mu \mathrm{g} / \mathrm{kg} \\
\mathrm{Q}\end{array}$ & $\begin{array}{c}\text { CB-156+172 } \\
\mu \mathrm{g} / \mathrm{kg} \\
\mathrm{Q}\end{array}$ & $\begin{array}{c}\operatorname{Vet}(\mathrm{BD}) \\
\mathrm{g} / \mathrm{kg} \\
\mathrm{Q}\end{array}$ & $\begin{array}{c}\text { Vet(soxhlet) } \\
\%\end{array}$ \\
\hline RQ20161128/088 & $2016 / 3420$ & Oesters & Eems-Dollard: Bocht van Watum & $<0.01$ & 0.03 & 0.7 & 0.3 & 1.4 & 0.03 & 0.1 & 0.5 & $<0.02$ & 0.04 & $<0.02$ & 0.6 & 0.03 & 7 & 0.6 \\
\hline RQ20161128/088 & $2016 / 3421$ & Oesters & Eems-Dollard: Bocht van Watum & $<0.01$ & 0.04 & 0.9 & 0.3 & 1.6 & 0.04 & 0.2 & 0.6 & $<0.02$ & 0.04 & $<0.02$ & 0.7 & 0.04 & 8 & 0.7 \\
\hline RQ20161128/088 & $2016 / 3422$ & Oesters & Eems-Dollard: Bocht van Watum & $<0.01$ & 0.03 & 0.6 & 0.2 & 1.2 & 0.03 & 0.1 & 0.4 & $<0.02$ & 0.03 & $<0.02$ & 0.5 & 0.03 & 6 & 0.5 \\
\hline
\end{tabular}

\begin{tabular}{|c|c|c|c|c|c|c|c|c|c|c|c|c|c|c|c|c|c|}
\hline & & & & $\begin{array}{c}\mathrm{CB}-28 \\
\mu \mathrm{g} / \mathrm{kg} \\
\mathrm{Q}\end{array}$ & $\begin{array}{c}\text { CB-31 } \\
\mu \mathrm{g} / \mathrm{kg} \\
\mathrm{Q}\end{array}$ & $\begin{array}{c}\mathrm{CB}-47 \\
\mu \mathrm{g} / \mathrm{kg} \\
\mathrm{Q}\end{array}$ & $\begin{array}{c}\text { CB- } 49 \\
\mu \mathrm{g} / \mathrm{kg} \\
\mathrm{Q}\end{array}$ & $\begin{array}{c}\text { CB-52 } \\
\mu g / k g \\
Q\end{array}$ & $\begin{array}{c}\text { CB- } 56 \\
\mu g / k g \\
Q\end{array}$ & $\begin{array}{c}\mathrm{CB}-85 \\
\mu \mathrm{g} / \mathrm{kg} \\
\mathrm{Q}\end{array}$ & $\begin{array}{c}\mathrm{CB}-87 \\
\mu g / \mathrm{kg} \\
\mathrm{Q}\end{array}$ & $\begin{array}{c}\text { CB- } 97 \\
\mu g / k g \\
Q\end{array}$ & $\begin{array}{c}\text { CB-101 } \\
\mu \mathrm{g} / \mathrm{kg} \\
\mathrm{Q}\end{array}$ & $\begin{array}{c}C B-105 \\
\mu g / k g \\
Q\end{array}$ & $\begin{array}{c}\text { CB-110 } \\
\mu \mathrm{g} / \mathrm{kg} \\
\mathrm{Q}\end{array}$ & $\begin{array}{c}\text { CB-118 } \\
\mu \mathrm{g} / \mathrm{kg} \\
\mathrm{Q}\end{array}$ & $\begin{array}{c}\text { CB- } 128+174 \\
\mu \mathrm{g} / \mathrm{kg} \\
\mathrm{Q}\end{array}$ \\
\hline RQ20161128/087 & 2016/3412 & Mosselen & Westerschelde: Knuitershoek & 4.6 & 3.5 & 1.3 & 2.2 & 3.1 & 1.5 & 0.5 & 1.1 & 1.3 & 6.8 & 0.8 & 5.4 & 3.3 & 1.2 \\
\hline RQ20161128/087 & $2016 / 3413$ & Mosselen & Westerschelde: Knuitershoek & 4.4 & 3.3 & 1.3 & 2.2 & 3.0 & 1.5 & 0.5 & 1.1 & 1.3 & 7.0 & 0.8 & 5.6 & 3.3 & 1.2 \\
\hline RQ20161128/087 & $2016 / 3414$ & Mosselen & Westerschelde: Knuitershoek & 3.9 & 2.9 & 1.3 & 2.1 & 2.9 & 1.5 & 0.5 & 1.1 & 1.3 & 6.8 & 0.8 & 5.4 & 3.2 & 1.2 \\
\hline RQ20161128/087 & $2016 / 3415$ & Mosselen & Westerschelde: Knuitershoek & 2.4 & 1.8 & 0.8 & 1.3 & 1.7 & 0.9 & 0.3 & 0.6 & 0.7 & 3.8 & 0.4 & 3.0 & 1.9 & 0.7 \\
\hline RQ20161128/087 & $2016 / 3416$ & Mosselen & Westerschelde: Knuitershoek & $\mathrm{nb}$ & $\mathrm{nb}$ & $\mathrm{nb}$ & $\mathrm{nb}$ & $\mathrm{nb}$ & $\mathrm{nb}$ & $\mathrm{nb}$ & $\mathrm{nb}$ & $\mathrm{nb}$ & $\mathrm{nb}$ & $\mathrm{nb}$ & $\mathrm{nb}$ & $\mathrm{nb}$ & $\mathrm{nb}$ \\
\hline
\end{tabular}

\begin{tabular}{|c|c|c|c|c|c|c|c|c|c|c|c|c|c|c|c|c|c|c|}
\hline & & & & $\begin{array}{c}\text { CB-137 } \\
\mu \mathrm{g} / \mathrm{kg} \\
\mathrm{Q}\end{array}$ & \begin{tabular}{|c|} 
CB-141 \\
$\mu \mathrm{g} / \mathrm{kg}$ \\
$\mathrm{Q}$
\end{tabular} & \begin{tabular}{|c|}
$C B-149$ \\
$\mu g / k g$ \\
$Q$
\end{tabular} & $\begin{array}{c}\text { CB-151 } \\
\mu \mathrm{g} / \mathrm{kg} \\
\mathrm{Q}\end{array}$ & \begin{tabular}{|c|}
$C B-153$ \\
$\mu g / k g$ \\
$Q$
\end{tabular} & \begin{tabular}{|c|}
$C B-170$ \\
$\mu g / k g$ \\
$Q$
\end{tabular} & \begin{tabular}{|c|} 
CB-180 \\
$\mu \mathrm{g} / \mathrm{kg}$ \\
$\mathrm{Q}$
\end{tabular} & $\begin{array}{c}\text { CB-187 } \\
\mu \mathrm{g} / \mathrm{kg} \\
\mathrm{Q}\end{array}$ & $\begin{array}{c}\text { CB-194 } \\
\mu \mathrm{g} / \mathrm{kg} \\
\mathrm{Q}\end{array}$ & $\begin{array}{c}\text { CB-202 } \\
\mu \mathrm{g} / \mathrm{kg} \\
\mathrm{Q}\end{array}$ & \begin{tabular}{|c|}
$\mathrm{CB}-206$ \\
$\mu \mathrm{g} / \mathrm{kg}$ \\
$\mathrm{Q}$
\end{tabular} & $\begin{array}{c}\text { CB-138 } \\
\mu \mathrm{g} / \mathrm{kg} \\
\mathrm{Q}\end{array}$ & $\begin{array}{c}\text { CB-156+172 } \\
\mu \mathrm{g} / \mathrm{kg} \\
\mathrm{Q}\end{array}$ & $\begin{array}{c}\text { Vet(BD) } \\
\mathrm{g} / \mathrm{kg} \\
\mathrm{Q}\end{array}$ & $\begin{array}{c}\text { Vet(soxhlet) } \\
\%\end{array}$ \\
\hline RQ20161128/087 & $2016 / 3412$ & Mosselen & Westerschelde: Knuitershoek & $<0.1$ & 0.2 & 12 & 3.6 & 22 & 0.5 & 2.5 & 6.4 & $<0.2$ & 0.3 & $<0.2$ & 10 & 0.6 & 18 & 1.8 \\
\hline RQ20161128/087 & $2016 / 3413$ & Mosselen & Westerschelde: Knuitershoek & $<0.1$ & 0.2 & 12 & 3.6 & 21 & 0.5 & 2.6 & 6.1 & $<0.2$ & 0.3 & $<0.2$ & 10 & 0.6 & 19 & 1.8 \\
\hline RQ20161128/087 & 2016/3414 & Mosselen & Westerschelde: Knuitershoek & $<0.1$ & 0.2 & 11 & 3.4 & 21 & 0.5 & 2.6 & 6.0 & $<0.2$ & 0.3 & $<0.2$ & 9.6 & 0.6 & 16 & 1.8 \\
\hline RQ20161128/087 & $2016 / 3415$ & Mosselen & Westerschelde: Knuitershoek & $<0.07$ & 0.1 & 6.5 & 2.0 & 12 & 0.3 & 1.5 & 3.6 & $<0.1$ & 0.2 & $<0.1$ & 5.7 & 0.3 & $\mathrm{nb}$ & 1.2 \\
\hline RQ20161128/087 & $2016 / 3416$ & Mosselen & Westerschelde: Knuitershoek & $\mathrm{nb}$ & $\mathrm{nb}$ & $\mathrm{nb}$ & $\mathrm{nb}$ & $\mathrm{nb}$ & nb & $\mathrm{nb}$ & $\mathrm{nb}$ & nb & nb & nb & nb & nb & $\mathrm{nb}$ & nb \\
\hline
\end{tabular}

\begin{tabular}{|c|c|c|c|c|c|c|c|c|c|c|c|c|c|c|c|c|c|c|}
\hline & & & & CB-28 & CB-31 & CB-47 & CB-49 & CB-52 & CB-56 & CB-85 & CB-87 & CB-97 & CB-101 & CB-105 & CB-110 & CB-118 & CB-128+174 & \\
\hline & & & & $\mu \mathrm{g} / \mathrm{kg}$ & $\mu \mathrm{g} / \mathrm{kg}$ & $\mu \mathrm{g} / \mathrm{kg}$ & $\mu \mathrm{g} / \mathrm{kg}$ & $\mu \mathrm{g} / \mathrm{kg}$ & $\mu \mathrm{g} / \mathrm{kg}$ & $\mu \mathrm{g} / \mathrm{kg}$ & $\mu \mathrm{g} / \mathrm{kg}$ & $\mu \mathrm{g} / \mathrm{kg}$ & $\mu \mathrm{g} / \mathrm{kg}$ & $\mu \mathrm{g} / \mathrm{kg}$ & $\mu \mathrm{g} / \mathrm{kg}$ & $\mu \mathrm{g} / \mathrm{kg}$ & $\mu \mathrm{g} / \mathrm{kg}$ & \\
\hline & & & & Q & Q & $\mathrm{Q}$ & $\mathrm{Q}$ & Q & $\mathrm{Q}$ & Q & $\mathrm{Q}$ & Q & Q & Q & $\mathrm{Q}$ & $\mathrm{Q}$ & Q & \\
\hline RQ20161128/089 & $2016 / 3426$ & Oesters & Westerschelde: Knuitershoek & 1.2 & 0.9 & 0.3 & 0.6 & 0.8 & 0.4 & 0.1 & 0.2 & 0.3 & 1.4 & 0.2 & 1.1 & 0.7 & 0.2 & \\
\hline RQ20161128/089 & $2016 / 3427$ & Oesters & Westerschelde: Knuitershoek & 1.2 & 0.9 & 0.3 & 0.6 & 1.1 & 0.4 & 0.1 & 0.2 & 0.3 & 1.4 & 0.1 & 1.1 & 0.6 & 0.2 & \\
\hline \multirow[t]{5}{*}{ RQ20161128/089 } & $2016 / 3428$ & Oesters & Westerschelde: Knuitershoek & 1.6 & 1.2 & 0.5 & 0.7 & 1.0 & 0.5 & 0.1 & 0.3 & 0.4 & 1.8 & 0.2 & 1.5 & 0.8 & 0.3 & \\
\hline & & & & & & & & & & & & & & & & & & \\
\hline & & & & CB-137 & CB-141 & CB-149 & CB-151 & CB-153 & CB-170 & CB-180 & CB-187 & CB-194 & CB-202 & CB-206 & CB-138 & CB-156+172 & Vet(BD) & Vet(soxhlet) \\
\hline & & & & $\mu \mathrm{g} / \mathrm{kg}$ & $\mu \mathrm{g} / \mathrm{kg}$ & $\mu \mathrm{g} / \mathrm{kg}$ & $\mu \mathrm{g} / \mathrm{kg}$ & $\mu \mathrm{g} / \mathrm{kg}$ & $\mu \mathrm{g} / \mathrm{kg}$ & $\mu \mathrm{g} / \mathrm{kg}$ & $\mu \mathrm{g} / \mathrm{kg}$ & $\mu \mathrm{g} / \mathrm{kg}$ & $\mu \mathrm{g} / \mathrm{kg}$ & $\mu \mathrm{g} / \mathrm{kg}$ & $\mu \mathrm{g} / \mathrm{kg}$ & $\mu \mathrm{g} / \mathrm{kg}$ & $\mathrm{g} / \mathrm{kg}$ & $\%$ \\
\hline & & & & $\mathrm{Q}$ & $\mathrm{Q}$ & Q & Q & Q & $\mathrm{Q}$ & Q & Q & Q & Q & Q & Q & Q & Q & \\
\hline RQ20161128/089 & $2016 / 3426$ & Oesters & Westerschelde: Knuitershoek & $<0.03$ & 0.2 & 2.4 & 0.8 & 4.2 & 0.1 & 0.6 & 1.3 & $<0.04$ & 0.07 & $<0.04$ & 1.4 & 0.09 & 0.6 & 0.5 \\
\hline RQ20161128/089 & $2016 / 3427$ & Oesters & Westerschelde: Knuitershoek & $<0.03$ & 0.2 & 2.3 & 0.8 & 4.0 & 0.09 & 0.5 & 1.2 & $<0.04$ & 0.07 & $<0.04$ & 1.4 & 0.08 & 0.6 & 0.5 \\
\hline RQ20161128/089 & $2016 / 3428$ & Oesters & Westerschelde: Knuitershoek & $<0.03$ & 0.2 & 3.0 & 1.0 & 5.1 & 0.1 & 0.7 & 1.5 & $<0.04$ & 0.08 & $<0.04$ & 1.8 & 0.1 & 0.8 & 0.7 \\
\hline
\end{tabular}




\begin{tabular}{|c|c|c|c|c|c|c|c|c|c|c|c|}
\hline & & & & $\begin{array}{c}\text { Kwik } \\
\mathrm{mg} / \mathrm{kg} \\
\mathrm{Q}\end{array}$ & $\begin{array}{c}\text { Cadmium } \\
\mathrm{mg} / \mathrm{kg} \\
\mathrm{Q}\end{array}$ & $\begin{array}{c}\text { Lood } \\
\mathrm{mg} / \mathrm{kg} \\
\mathrm{Q}\end{array}$ & $\begin{array}{c}\text { Koper } \\
\mathrm{mg} / \mathrm{kg} \\
\mathrm{Q}\end{array}$ & $\begin{array}{c}\text { Zink } \\
\mathrm{mg} / \mathrm{kg} \\
\mathrm{Q}\end{array}$ & $\begin{array}{c}\text { Chroom } \\
\mathrm{mg} / \mathrm{kg} \\
\mathrm{Q}\end{array}$ & $\begin{array}{c}\text { Arseen } \\
\mathrm{mg} / \mathrm{kg} \\
\mathrm{Q}\end{array}$ & $\begin{array}{l}\text { Nikke } \\
\mathrm{mg} / \mathrm{kg}\end{array}$ \\
\hline RQ20161128/088 & Eems-Dollard: Bocht van Watum & $2016 / 3420$ & Oesters & 0.0089 & 0.43 & 0.15 & 35 & 275 & 0.16 & 1.1 & 0.15 \\
\hline RQ20161128/088 & Eems-Dollard: Bocht van Watum & $2016 / 3421$ & Oesters & 0.010 & 0.49 & 0.21 & 37 & 281 & 0.21 & 1.2 & 0.17 \\
\hline RQ20161128/088 & Eems-Dollard: Bocht van Watum & $2016 / 3422$ & Oesters & 0.0075 & 0.41 & 0.11 & 31 & 250 & 0.11 & 1.1 & 0.12 \\
\hline
\end{tabular}

\begin{tabular}{|c|c|c|c|c|c|c|c|c|}
\hline & & & & $\begin{array}{c}\text { Droge stof } \\
\% \\
\mathrm{Q}\end{array}$ & $\begin{array}{l}\text { As } \\
\% \\
\text { Q }\end{array}$ & $\begin{array}{c}\text { Asvrijdrooggewicht } \\
\%\end{array}$ & $\begin{array}{c}\text { Vet(BD) } \\
\mathrm{g} / \mathrm{kg} \\
\mathrm{Q}\end{array}$ & $\begin{array}{c}\text { Vet(soxhlet) } \\
\%\end{array}$ \\
\hline RQ20161128/088 & Eems-Dollard: Bocht van Watum & $2016 / 3420$ & Oesters & 8.7 & 2.6 & 6.1 & 7 & 0.6 \\
\hline RQ20161128/088 & Eems-Dollard: Bocht van Watum & $2016 / 3421$ & Oesters & 9.4 & 2.6 & 6.8 & 8 & 0.7 \\
\hline RQ20161128/088 & Eems-Dollard: Bocht van Watum & $2016 / 3422$ & Oesters & 8.0 & 2.3 & 5.7 & 6 & 0.5 \\
\hline
\end{tabular}

\begin{tabular}{|c|c|c|c|c|c|c|c|c|c|c|c|}
\hline & & & & $\begin{array}{c}\text { Kwik } \\
\mathrm{mg} / \mathrm{kg} \\
\mathrm{Q}\end{array}$ & $\begin{array}{c}\text { Cadmium } \\
\mathrm{mg} / \mathrm{kg} \\
\mathrm{Q}\end{array}$ & $\begin{array}{c}\text { Lood } \\
\mathrm{mg} / \mathrm{kg} \\
\mathrm{Q}\end{array}$ & $\begin{array}{c}\text { Koper } \\
\mathrm{mg} / \mathrm{kg} \\
\mathrm{Q}\end{array}$ & $\begin{array}{c}\text { Zink } \\
\mathrm{mg} / \mathrm{kg} \\
\mathrm{Q}\end{array}$ & $\begin{array}{c}\text { Chroom } \\
\mathrm{mg} / \mathrm{kg} \\
\mathrm{Q}\end{array}$ & $\begin{array}{c}\text { Arseen } \\
\mathrm{mg} / \mathrm{kg} \\
\mathrm{Q}\end{array}$ & $\begin{array}{l}\text { Nikke } \\
\mathrm{mg} / \mathrm{kg}\end{array}$ \\
\hline RQ20161128/089 & Westerschelde: Knuitershoek & 2016/3426 & Oesters & 0.0097 & 1.0 & 0.12 & 44 & 385 & 0.11 & 1.2 & 0.10 \\
\hline RQ20161128/089 & Westerschelde: Knuitershoek & 2016/3427 & Oesters & 0.010 & 0.96 & 0.10 & 50 & 390 & 0.075 & 1.2 & 0.10 \\
\hline RQ20161128/089 & Westerschelde: Knuitershoek & 2016/3428 & Oesters & 0.010 & 1.0 & 0.11 & 51 & 432 & 0.088 & 1.3 & 0.10 \\
\hline
\end{tabular}

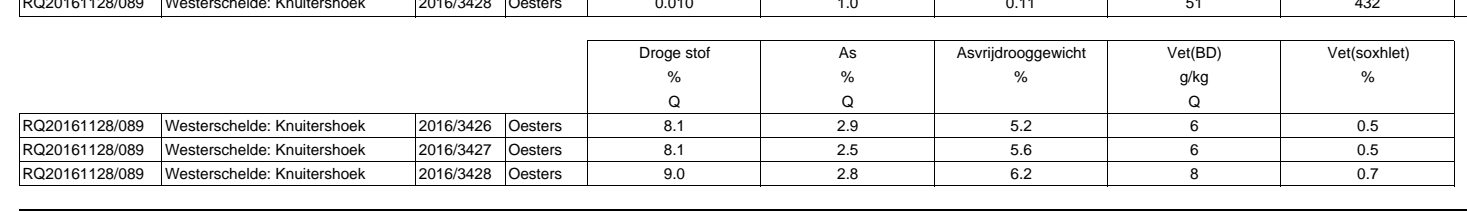

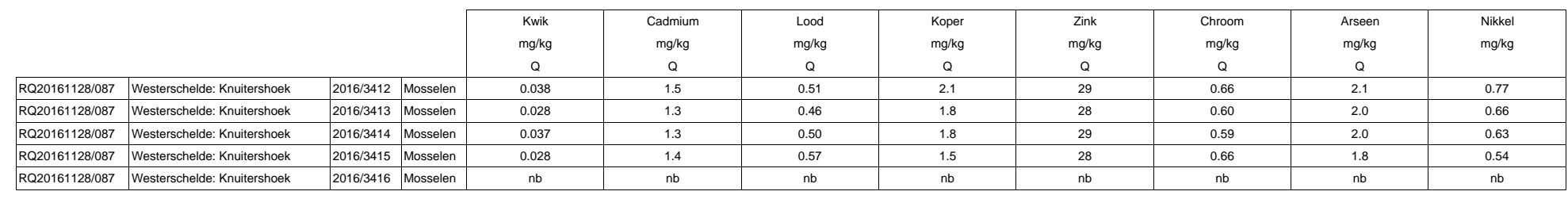

\begin{tabular}{|c|c|c|c|c|c|c|c|c|}
\hline & & & & $\begin{array}{c}\text { Droge stof } \\
\% \\
\text { Q }\end{array}$ & $\begin{array}{l}\text { As } \\
\% \\
\text { Q }\end{array}$ & $\begin{array}{c}\text { Asvrijdrooggewicht } \\
\%\end{array}$ & $\begin{array}{c}\operatorname{Vet}(\mathrm{BD}) \\
\mathrm{g} / \mathrm{kg} \\
\mathrm{Q}\end{array}$ & $\begin{array}{c}\text { Vet(soxhlet) } \\
\%\end{array}$ \\
\hline RQ20161128/087 & Westerschelde: Knuitershoek & $2016 / 3412$ & Mosselen & 17.8 & 3.2 & 14.6 & 18 & 1.8 \\
\hline RQ20161128/087 & Westerschelde: Knuitershoek & $2016 / 3413$ & Mosselen & 17.1 & 2.9 & 14.2 & 19 & 1.8 \\
\hline RQ20161128/087 & Westerschelde: Knuitershoek & $2016 / 3414$ & Mosselen & 17.3 & 3.1 & 14.2 & 16 & 1.8 \\
\hline RQ20161128/087 & Westerschelde: Knuitershoek & $2016 / 3415$ & Mosselen & 12.5 & 3.0 & 9.5 & $\mathrm{nb}$ & 1.2 \\
\hline RQ20161128/087 & Westerschelde: Knuitershoek & 2016/3416 & Mosselen & $\mathrm{nb}$ & $\mathrm{nb}$ & $\mathrm{nb}$ & $\mathrm{nb}$ & $\mathrm{nb}$ \\
\hline
\end{tabular}

\section{$Q=1 S 017025$}

$\mathrm{nb}=$ niet bepaald 


\begin{tabular}{|c|c|c|c|c|c|c|c|c|c|c|}
\hline & & & & $\begin{array}{c}\text { Anthraceen } \\
\mu \mathrm{g} / \mathrm{kg} \\
\mathrm{Q} \\
\end{array}$ & \begin{tabular}{|c} 
Fluoranteen \\
$\mu \mathrm{g} / \mathrm{kg}$ \\
$\mathrm{Q}$
\end{tabular} & $\begin{array}{c}\text { Benzo(b)fluoranteen } \\
\mu \mathrm{g} / \mathrm{kg} \\
\mathrm{Q} \\
\end{array}$ & $\begin{array}{c}\text { Benzo(k)fluoranteen } \\
\mu \mathrm{g} / \mathrm{kg} \\
\mathrm{Q}\end{array}$ & $\begin{array}{c}\text { Benzo(a)pyreen } \\
\mu \mathrm{g} / \mathrm{kg} \\
\mathrm{Q} \\
\end{array}$ & $\begin{array}{c}\text { Benzo(g,h,i)peryleen } \\
\mu \mathrm{g} / \mathrm{kg} \\
\mathrm{Q}\end{array}$ & $\begin{array}{c}\text { Indeno(1,2,3-cd)pyreen } \\
\mu \mathrm{g} / \mathrm{kg}\end{array}$ \\
\hline RQ20161128/088 & Eems-Dollard: Bocht van Watum & $2016 / 3420$ & Oesters & 0.2 & 4.3 & 3.6 & 1.5 & 0.03 & 1.4 & 1.4 \\
\hline RQ20161128/088 & Eems-Dollard: Bocht van Watum & $2016 / 3421$ & Oesters & 0.4 & 6.4 & 5.3 & 2.0 & 1.7 & 2.2 & 2.6 \\
\hline RQ20161128/088 & Eems-Dollard: Bocht van Watum & $2016 / 3422$ & Oesters & 0.1 & 3.5 & 2.5 & 0.9 & 0.8 & 0.9 & 0.9 \\
\hline
\end{tabular}

\begin{tabular}{|c|c|c|c|c|c|c|c|c|c|}
\hline & & & $\begin{array}{c}\text { Acenafteen } \\
\mu \mathrm{g} / \mathrm{kg} \\
\mathrm{Q}\end{array}$ & $\begin{array}{c}\text { Fluoreen } \\
\mu \mathrm{g} / \mathrm{kg} \\
\mathrm{Q}\end{array}$ & $\begin{array}{c}\text { Fenantreen } \\
\mu \mathrm{g} / \mathrm{kg} \\
\mathrm{Q}\end{array}$ & $\begin{array}{c}\text { Pyreen } \\
\mu \mathrm{g} / \mathrm{kg} \\
\mathrm{Q}\end{array}$ & $\begin{array}{c}\text { Benzo(a)anthraceen } \\
\mu \mathrm{g} / \mathrm{kg} \\
\mathrm{Q}\end{array}$ & $\begin{array}{c}\text { Chryseen } \\
\mu \mathrm{g} / \mathrm{kg} \\
\mathrm{Q}\end{array}$ & $\begin{array}{c}\text { Dibenz }(\mathrm{a}, \mathrm{h}) \text { anthraceen } \\
\mu \mathrm{g} / \mathrm{kg}\end{array}$ \\
\hline RQ20161128/088 & Eems-Dollard: Bocht van Watum & 2016/3420 Oesters & $<0.2$ & $<0.5$ & $<4.2$ & 4.1 & 2.3 & 1.3 & 0.1 \\
\hline RQ20161128/088 & Eems-Dollard: Bocht van Watum & 2016/3421 Oesters & $<0.2$ & 0.6 & $<4.2$ & 5.7 & 2.5 & 1.7 & 0.2 \\
\hline RQ20161128/088 & Eems-Dollard: Bocht van Watum & 2016/3422 Oesters & $<0.2$ & $<0.5$ & $<4.1$ & 3.1 & 0.7 & 0.6 & 0.2 \\
\hline
\end{tabular}

\begin{tabular}{|c|c|c|c|c|c|c|c|c|c|}
\hline & & & $\begin{array}{c}\text { Anthraceen } \\
\mu \mathrm{g} / \mathrm{kg} \\
\mathrm{Q}\end{array}$ & $\begin{array}{c}\text { Fluoranteen } \\
\mu \mathrm{g} / \mathrm{kg} \\
\mathrm{Q}\end{array}$ & $\begin{array}{c}\text { Benzo(b)fluoranteen } \\
\mu \mathrm{g} / \mathrm{kg} \\
\mathrm{Q}\end{array}$ & $\begin{array}{c}\text { Benzo(k)fluoranteen } \\
\mu \mathrm{g} / \mathrm{kg} \\
\mathrm{Q}\end{array}$ & $\begin{array}{c}\text { Benzo(a)pyreen } \\
\mu \mathrm{g} / \mathrm{kg} \\
\mathrm{Q}\end{array}$ & $\begin{array}{c}\text { Benzo }(\mathrm{g}, \mathrm{h}, \mathrm{i}) \text { peryleen } \\
\mu \mathrm{g} / \mathrm{kg} \\
\mathrm{Q}\end{array}$ & $\begin{array}{c}\text { Indeno(1,2,3-cd)pyreen } \\
\mu \mathrm{g} / \mathrm{kg}\end{array}$ \\
\hline RQ20161128/089 & Westerschelde: Knuitershoek & 2016/3426 Oesters & $<0.5$ & 10 & 4.0 & 1.3 & 1.5 & 1.2 & 1.1 \\
\hline RQ20161128/089 & Westerschelde: Knuitershoek & 2016/3427 Oesters & $<0.5$ & 10 & 3.9 & 1.3 & 1.5 & 1.2 & 1.1 \\
\hline RQ20161128/089 & Westerschelde: Knuitershoek & 2016/3428 Oesters & $<0.4$ & 11 & 4.3 & 1.4 & 1.7 & 1.2 & 1.1 \\
\hline
\end{tabular}

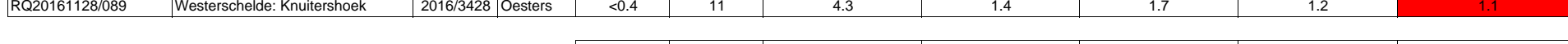

\begin{tabular}{|c|c|c|c|c|c|c|c|c|c|c|}
\hline & & & & $\begin{array}{c}\text { Acenafteen } \\
\mu \mathrm{g} / \mathrm{kg} \\
\mathrm{Q} \\
\end{array}$ & $\begin{array}{c}\text { Fluoreen } \\
\mu \mathrm{g} / \mathrm{kg} \\
\mathrm{Q} \\
\end{array}$ & $\begin{array}{c}\text { Fenantreen } \\
\mu \mathrm{g} / \mathrm{kg} \\
\mathrm{Q} \\
\end{array}$ & $\begin{array}{c}\text { Pyreen } \\
\mu g / k g \\
Q\end{array}$ & $\begin{array}{c}\text { Benzo(a)anthraceen } \\
\mu \mathrm{g} / \mathrm{kg} \\
\mathrm{Q} \\
\end{array}$ & $\begin{array}{c}\text { Chryseen } \\
\mu g / k g \\
Q\end{array}$ & $\begin{array}{c}\text { Dibenz(a,h)anthraceen } \\
\mu \mathrm{g} / \mathrm{kg}\end{array}$ \\
\hline RQ20161128/089 & Westerschelde: Knuitershoek & $2016 / 3426$ & Oesters & 0.2 & $<0.6$ & $<11$ & 9.2 & 3.3 & 2.1 & $<0.1$ \\
\hline RQ20161128/089 & Westerschelde: Knuitershoek & $2016 / 3427$ & Oesters & 0.2 & $<0.6$ & $<11$ & 9.0 & 3.2 & 2.1 & $<0.1$ \\
\hline RQ20161128/089 & Westerschelde: Knuitershoek & $2016 / 3428$ & Oesters & 0.2 & $<0.5$ & $<10$ & 10 & 3.6 & 2.3 & 0.1 \\
\hline
\end{tabular}

\begin{tabular}{|c|c|c|c|c|c|c|c|c|c|}
\hline & & & $\begin{array}{c}\text { Anthraceen } \\
\mu \mathrm{g} / \mathrm{kg} \\
\mathrm{Q}\end{array}$ & $\begin{array}{c}\text { Fluoranteen } \\
\mu \mathrm{g} / \mathrm{kg} \\
\mathrm{Q}\end{array}$ & $\begin{array}{c}\text { Benzo(b)fluoranteen } \\
\mu \mathrm{g} / \mathrm{kg} \\
\mathrm{Q}\end{array}$ & $\begin{array}{c}\text { Benzo(k)fluoranteen } \\
\mu \mathrm{g} / \mathrm{kg} \\
\mathrm{Q}\end{array}$ & $\begin{array}{c}\text { Benzo(a)pyreen } \\
\mu \mathrm{g} / \mathrm{kg} \\
\mathrm{Q}\end{array}$ & $\begin{array}{c}\text { Benzo }(\mathrm{g}, \mathrm{h}, \mathrm{i}) \text { peryleen } \\
\mu \mathrm{g} / \mathrm{kg} \\
\mathrm{Q}\end{array}$ & $\begin{array}{c}\text { Indeno(1,2,3-cd)pyreer } \\
\mu \mathrm{g} / \mathrm{kg}\end{array}$ \\
\hline RQ20161128/087 & Westerschelde: Knuitershoek & \begin{tabular}{|l|l|} 
2016/3412 & Mosselen \\
\end{tabular} & 1.2 & 31 & 12 & 3.8 & 5.5 & 6.4 & 5.2 \\
\hline \begin{tabular}{|l|} 
RQ20161128/087 \\
\end{tabular} & Westerschelde: Knuitershoek & \begin{tabular}{|l|l|} 
2016/3413 & Mosselen \\
\end{tabular} & 1.1 & 32 & 15 & 0.2 & 0.2 & 7.1 & 5.4 \\
\hline RQ20161128/087 & Westerschelde: Knuitershoek & \begin{tabular}{|l|l|} 
2016/3414 & Mosselen \\
\end{tabular} & 1.1 & 28 & 10 & 3.3 & 4.4 & 5.2 & 3.9 \\
\hline RQ20161128/087 & Westerschelde: Knuitershoek & \begin{tabular}{|l|l|} 
2016/3415 & Mosselen \\
\end{tabular} & 0.9 & 22 & 8.3 & 2.6 & 3.7 & 4.8 & 3.5 \\
\hline RQ20161128/087 & Westerschelde: Knuitershoek & \begin{tabular}{|l|l|} 
2016/3416 & Mosselen \\
\end{tabular} & $\mathrm{nb}$ & $\mathrm{nb}$ & $\mathrm{nb}$ & $\mathrm{nb}$ & $\mathrm{nb}$ & $\mathrm{nb}$ & $\mathrm{nb}$ \\
\hline
\end{tabular}

\begin{tabular}{|c|c|c|c|c|c|c|c|c|c|c|}
\hline Rez & jovesterscrielue. Anumer & $2010 / 3410$ & |ivussetent & ( & 皮 & miv & MII & Mis & MIS & MIS \\
\hline & & & & $\begin{array}{c}\text { Acenafteen } \\
\mu \mathrm{g} / \mathrm{kg} \\
\mathrm{Q}\end{array}$ & $\begin{array}{c}\text { Fluoreen } \\
\mu \mathrm{g} / \mathrm{kg} \\
\mathrm{Q}\end{array}$ & $\begin{array}{c}\text { Fenantreen } \\
\mu \mathrm{g} / \mathrm{kg} \\
\mathrm{Q}\end{array}$ & $\begin{array}{c}\text { Pyreen } \\
\mu \mathrm{g} / \mathrm{kg} \\
\mathrm{Q}\end{array}$ & $\begin{array}{c}\text { Benzo(a)anthraceen } \\
\mu \mathrm{g} / \mathrm{kg} \\
\mathrm{Q}\end{array}$ & $\begin{array}{c}\text { Chryseen } \\
\mu \mathrm{g} / \mathrm{kg} \\
\mathrm{Q}\end{array}$ & $\begin{array}{c}\text { Dibenz(a,h)anthraceen } \\
\mu \mathrm{g} / \mathrm{kg}\end{array}$ \\
\hline RQ20161128/087 & Westerschelde: Knuitershoek & $2016 / 3412$ & Mosselen & 0.3 & 1.4 & $<9.3$ & 30 & 10 & 7.1 & 0.3 \\
\hline RQ20161128/087 & Westerschelde: Knuitershoek & $2016 / 3413$ & Mosselen & 0.3 & 1.6 & 13 & 34 & 11 & 7.4 & 0.4 \\
\hline RQ20161128/087 & Westerschelde: Knuitershoek & $2016 / 3414$ & Mosselen & 0.5 & 1.5 & $<9.8$ & 27 & 8.6 & 5.7 & 0.2 \\
\hline RQ20161128/087 & Westerschelde: Knuitershoek & $2016 / 3415$ & Mosselen & 0.4 & 1.2 & $<16$ & 22 & 6.8 & 4.4 & $<0.2$ \\
\hline RQ20161128/087 & Westerschelde: Knuitershoek & $2016 / 3416$ & Mosselen & nb & nb & nb & $\mathrm{nb}$ & $\mathrm{nb}$ & nb & $\mathrm{nb}$ \\
\hline
\end{tabular}

$\begin{array}{ll}\mathrm{Q}=\text { ISO17025 } & \\ \mathrm{nb} & \text { Indicatief } \\ & \text { Niet bepaald }\end{array}$


Bijlage 5. Gehalten OCP's en PBDE's in mosselen en oesters in $\mu \mathrm{g} / \mathrm{kg}$ (onderzoek najaar 2016).

\begin{tabular}{|c|c|c|c|c|c|c|c|c|c|c|c|c|c|c|c|}
\hline & & & & $\begin{array}{c}\mathrm{QCB} \\
\mu \mathrm{g} / \mathrm{kg} \\
\mathrm{Q}\end{array}$ & $\begin{array}{c}\mathrm{HCB} \\
\mu \mathrm{g} / \mathrm{kg} \\
\mathrm{Q}\end{array}$ & $\begin{array}{c}\mathrm{HCBD} \\
\mu \mathrm{g} / \mathrm{kg} \\
\mathrm{Q}\end{array}$ & $\begin{array}{c}\mathrm{a}-\mathrm{HCH} \\
\mu \mathrm{g} / \mathrm{kg} \\
\mathrm{Q}\end{array}$ & $\begin{array}{c}\mathrm{b}-\mathrm{HCH} \\
\mu \mathrm{g} / \mathrm{kg} \\
\mathrm{Q}\end{array}$ & $\begin{array}{c}\mathrm{y}-\mathrm{HCH} \\
\mu \mathrm{g} / \mathrm{kg} \\
Q\end{array}$ & $\begin{array}{c}\text { Dieldrin } \\
\mu \mathrm{g} / \mathrm{kg}\end{array}$ & $\begin{array}{c}\mathrm{b}-\mathrm{HEPO} \\
\mu \mathrm{g} / \mathrm{kg} \\
\mathrm{Q}\end{array}$ & $\begin{array}{c}\text { Heptachloor } \\
\mu \mathrm{g} / \mathrm{kg} \\
\mathrm{Q}\end{array}$ & $\begin{array}{c}\text { pp_DDE } \\
\mu \mathrm{g} / \mathrm{kg} \\
\mathrm{Q}\end{array}$ & $\begin{array}{c}\text { pp_DDD } \\
\mu \mathrm{g} / \mathrm{kg} \\
\mathrm{Q}\end{array}$ & $\begin{array}{c}\text { pp_DDT } \\
\mu \mathrm{g} / \mathrm{kg}\end{array}$ \\
\hline RQ20161128/088 & Eems-Dollard: Bocht van Watum & $2016 / 3420$ & Oesters & $<0.006$ & $<0.01$ & $<0.006$ & $<0.01$ & $<0.02$ & $<0.01$ & 0.08 & $<0.01$ & $<0.006$ & 0.3 & 0.08 & $<0.04$ \\
\hline RQ20161128/088 & Eems-Dollard: Bocht van Watum & $2016 / 3421$ & Oesters & $<0.006$ & $<0.01$ & $<0.006$ & $<0.01$ & $<0.02$ & $<0.01$ & 0.09 & $<0.01$ & $<0.006$ & 0.4 & 0.1 & $<0.04$ \\
\hline RQ20161128/088 & Eems-Dollard: Bocht van Watum & $2016 / 3422$ & Oesters & $<0.006$ & $<0.006$ & $<0.006$ & $<0.01$ & $<0.02$ & $<0.01$ & 0.06 & $<0.01$ & $<0.006$ & 0.2 & 0.07 & $<0.04$ \\
\hline
\end{tabular}

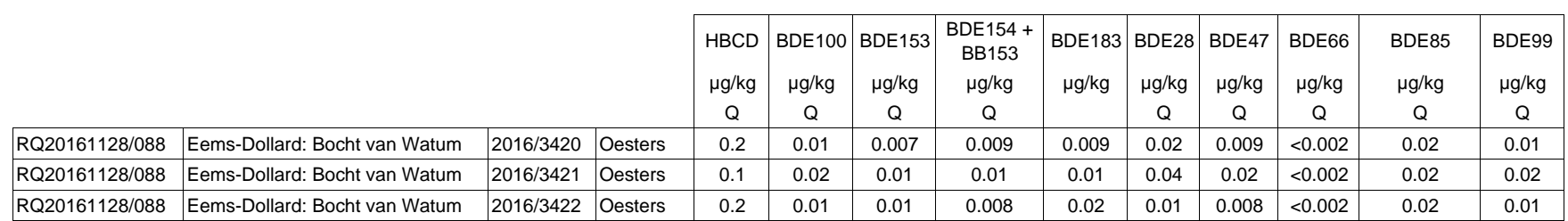

\begin{tabular}{|c|c|c|c|c|c|c|c|c|c|c|c|c|c|c|c|}
\hline & & & & $\begin{array}{l}\mathrm{QCB} \\
\mu \mathrm{g} / \mathrm{kg} \\
\mathrm{QCB}\end{array}$ & $\begin{array}{c}\mathrm{HCB} \\
\mu \mathrm{g} / \mathrm{kg} \\
\mathrm{Q}\end{array}$ & $\begin{array}{c}\mathrm{HCBD} \\
\mu \mathrm{g} / \mathrm{kg} \\
\mathrm{Q}\end{array}$ & $\begin{array}{c}\mathrm{a}-\mathrm{HCH} \\
\mu \mathrm{g} / \mathrm{kg} \\
\mathrm{Q}\end{array}$ & $\begin{array}{c}\mathrm{b}-\mathrm{HCH} \\
\mu \mathrm{g} / \mathrm{kg} \\
\mathrm{Q}\end{array}$ & $\begin{array}{c}y-\mathrm{HCH} \\
\mu \mathrm{g} / \mathrm{kg} \\
Q\end{array}$ & $\begin{array}{c}\text { Dieldrin } \\
\mu \mathrm{g} / \mathrm{kg}\end{array}$ & $\begin{array}{c}\mathrm{b}-\mathrm{HEPO} \\
\mu \mathrm{g} / \mathrm{kg} \\
\mathrm{Q}\end{array}$ & $\begin{array}{c}\text { Heptachloor } \\
\mu \mathrm{g} / \mathrm{kg} \\
\mathrm{Q}\end{array}$ & $\begin{array}{c}p p \_D D E \\
\mu g / k g \\
Q\end{array}$ & $\begin{array}{c}\text { pp_DDD } \\
\mu \mathrm{g} / \mathrm{kg} \\
\mathrm{Q}\end{array}$ & $\begin{array}{c}p_{-}{ }^{2} \text { DDT } \\
\mu \mathrm{g} / \mathrm{kg}\end{array}$ \\
\hline RQ20161128/089 & Westerschelde: Knuitershoek & $2016 / 3426$ & Oesters & $<0.01$ & $<0.01$ & $<0.01$ & $<0.01$ & $<0.02$ & $<0.01$ & 0.1 & 0.03 & $<0.01$ & 0.6 & 0.2 & $<0.03$ \\
\hline RQ20161128/089 & Westerschelde: Knuitershoek & $2016 / 3427$ & Oesters & $<0.01$ & $<0.01$ & $<0.01$ & $<0.01$ & $<0.02$ & $<0.01$ & 0.1 & 0.03 & $<0.01$ & 0.5 & 0.2 & $<0.04$ \\
\hline RQ20161128/089 & Westerschelde: Knuitershoek & $2016 / 3428$ & Oesters & $<0.02$ & $<0.02$ & $<0.02$ & $<0.01$ & $<0.03$ & $<0.01$ & 0.2 & 0.04 & $<0.02$ & 0.8 & 0.2 & $<0.04$ \\
\hline
\end{tabular}

\begin{tabular}{|c|c|c|c|c|c|c|c|c|c|c|c|c|c|}
\hline & & & & $\begin{array}{c}\mathrm{HBCD} \\
\mu \mathrm{g} / \mathrm{kg} \\
\mathrm{Q}\end{array}$ & $\begin{array}{c}\text { BDE100 } \\
\mu \mathrm{g} / \mathrm{kg} \\
\mathrm{Q}\end{array}$ & $\begin{array}{c}\text { BDE153 } \\
\mu \mathrm{g} / \mathrm{kg} \\
\mathrm{Q}\end{array}$ & $\begin{array}{c}\text { BDE154 + } \\
\text { BB153 } \\
\mu \mathrm{g} / \mathrm{kg} \\
\mathrm{Q}\end{array}$ & $\begin{array}{c}\text { BDE183 } \\
\mu \mathrm{g} / \mathrm{kg}\end{array}$ & $\begin{array}{c}\text { BDE28 } \\
\mu \mathrm{g} / \mathrm{kg} \\
\mathrm{Q} \\
\end{array}$ & $\begin{array}{c}\text { BDE47 } \\
\mu \mathrm{g} / \mathrm{kg} \\
\mathrm{Q}\end{array}$ & $\begin{array}{c}\text { BDE66 } \\
\mu \mathrm{g} / \mathrm{kg} \\
\mathrm{Q}\end{array}$ & $\begin{array}{c}\text { BDE85 } \\
\mu \mathrm{g} / \mathrm{kg} \\
\mathrm{Q}\end{array}$ & $\begin{array}{c}\text { BDE99 } \\
\mu \mathrm{g} / \mathrm{kg} \\
\mathrm{Q}\end{array}$ \\
\hline RQ20161128/089 & Westerschelde: Knuitershoek & $2016 / 3426$ & Oesters & 0.3 & 0.02 & 0.02 & 0.03 & 0.03 & 0.01 & 0.06 & $<0.002$ & 0.008 & 0.02 \\
\hline RQ20161128/089 & Westerschelde: Knuitershoek & $2016 / 3427$ & Oesters & 0.4 & 0.03 & 0.01 & 0.02 & 0.02 & 0.01 & 0.07 & $<0.002$ & 0.01 & 0.03 \\
\hline RQ20161128/089 & Westerschelde: Knuitershoek & 2016/3428 & Oesters & 0.7 & 0.03 & 0.1 & 0.05 & 0.2 & 0.01 & 0.07 & $<0.002$ & 0.01 & 0.03 \\
\hline
\end{tabular}

RQ20161128/087 Westerschelde: Knuitershoek RQ20161128/087 Westerschelde: Knuitershoek RQ20161128/087 Westerschelde: Knuitershoek RQ20161128/087 Westerschelde: Knuitershoek \begin{tabular}{|l|l|}
\hline RQ20161128/087 & Westerschelde: Knuitershoek \\
\hline
\end{tabular}

\begin{tabular}{|c|c|c|c|c|c|c|c|c|c|c|c|}
\hline $\begin{array}{c}\mathrm{QCB} \\
\mu \mathrm{g} / \mathrm{kg} \\
\mathrm{Q}\end{array}$ & $\begin{array}{c}\mathrm{HCB} \\
\mu \mathrm{g} / \mathrm{kg} \\
\mathrm{Q}\end{array}$ & $\begin{array}{c}\text { HCBD } \\
\mu g / k g \\
Q\end{array}$ & $\begin{array}{c}\mathrm{a}-\mathrm{HCH} \\
\mu \mathrm{g} / \mathrm{kg} \\
\mathrm{Q}\end{array}$ & $\begin{array}{c}\mathrm{b}-\mathrm{HCH} \\
\mu \mathrm{g} / \mathrm{kg} \\
\mathrm{Q}\end{array}$ & $\begin{array}{c}y-\mathrm{HCH} \\
\mu \mathrm{g} / \mathrm{kg} \\
\mathrm{Q}\end{array}$ & $\begin{array}{c}\text { Dieldrin } \\
\mu \mathrm{g} / \mathrm{kg}\end{array}$ & $\begin{array}{c}\mathrm{b}-\mathrm{HEPO} \\
\mu \mathrm{g} / \mathrm{kg} \\
\mathrm{Q}\end{array}$ & $\begin{array}{c}\text { Heptachloor } \\
\mu \mathrm{g} / \mathrm{kg} \\
\mathrm{Q}\end{array}$ & $\begin{array}{c}\text { pp_DDE } \\
\mu \mathrm{g} / \mathrm{kg} \\
\mathrm{Q}\end{array}$ & $\begin{array}{c}\text { pp_DDD } \\
\mu \mathrm{g} / \mathrm{kg} \\
\mathrm{Q}\end{array}$ & $\begin{array}{c}\text { pp_DDT } \\
\mu \mathrm{g} / \mathrm{kg}\end{array}$ \\
\hline$<0.06$ & $<0.06$ & $<0.06$ & $<0.02$ & $<0.05$ & $<0.04$ & 0.5 & 0.1 & $<0.06$ & 2.3 & 0.8 & $<0.07$ \\
\hline$<0.06$ & $<0.06$ & $<0.06$ & $<0.02$ & $<0.05$ & $<0.04$ & 0.5 & 0.1 & $<0.06$ & 2.3 & 0.7 & $<0.07$ \\
\hline$<0.06$ & $<0.06$ & $<0.06$ & $<0.03$ & $<0.05$ & $<0.05$ & 0.5 & 0.1 & $<0.06$ & 2.4 & 0.7 & $<0.08$ \\
\hline$<0.03$ & $<0.03$ & $<0.03$ & $<0.03$ & $<0.06$ & $<0.04$ & 0.3 & 0.06 & $<0.03$ & 1.3 & 0.4 & $<0.09$ \\
\hline $\mathrm{nb}$ & $\mathrm{nb}$ & $\mathrm{nb}$ & $\mathrm{nb}$ & $\mathrm{nb}$ & $\mathrm{nb}$ & $\mathrm{nb}$ & $\mathrm{nb}$ & $\mathrm{nb}$ & $\mathrm{nb}$ & $\mathrm{nb}$ & $\mathrm{nb}$ \\
\hline
\end{tabular}

\begin{tabular}{|c|c|c|c|c|c|c|c|c|c|c|c|c|c|}
\hline & & & & $\begin{array}{c}\mathrm{HBCD} \\
\mu \mathrm{g} / \mathrm{kg} \\
\mathrm{Q}\end{array}$ & $\begin{array}{c}\text { BDE100 } \\
\mu \mathrm{g} / \mathrm{kg} \\
\mathrm{Q}\end{array}$ & $\begin{array}{c}\text { BDE153 } \\
\mu \mathrm{g} / \mathrm{kg} \\
\mathrm{Q}\end{array}$ & $\begin{array}{c}\text { BDE154 + } \\
\text { BB153 } \\
\mu \mathrm{g} / \mathrm{kg} \\
\mathrm{Q}\end{array}$ & $\begin{array}{c}\text { BDE183 } \\
\mu \mathrm{g} / \mathrm{kg}\end{array}$ & $\begin{array}{c}\text { BDE28 } \\
\mu \mathrm{g} / \mathrm{kg} \\
\mathrm{Q}\end{array}$ & $\begin{array}{c}\text { BDE47 } \\
\mu \mathrm{g} / \mathrm{kg} \\
\mathrm{Q}\end{array}$ & $\begin{array}{c}\text { BDE66 } \\
\mu \mathrm{g} / \mathrm{kg} \\
\mathrm{Q}\end{array}$ & $\begin{array}{c}\text { BDE85 } \\
\mu \mathrm{g} / \mathrm{kg} \\
\mathrm{Q}\end{array}$ & $\begin{array}{c}\text { BDE99 } \\
\mu \mathrm{g} / \mathrm{kg} \\
\mathrm{Q}\end{array}$ \\
\hline RQ20161128/087 & Westerschelde: Knuitershoek & $2016 / 3412$ & Mosselen & 1.1 & 0.1 & 0.02 & 0.06 & 0.009 & 0.03 & 0.2 & $<0.002$ & 0.02 & 0.1 \\
\hline RQ20161128/087 & Westerschelde: Knuitershoek & $2016 / 3413$ & Mosselen & 1.2 & 0.09 & 0.03 & 0.06 & 0.04 & 0.02 & 0.2 & $<0.002$ & 0.02 & 0.1 \\
\hline RQ20161128/087 & Westerschelde: Knuitershoek & $2016 / 3414$ & Mosselen & 1.1 & 0.09 & 0.04 & 0.06 & 0.07 & 0.02 & 0.3 & $<0.002$ & 0.02 & 0.1 \\
\hline RQ20161128/087 & Westerschelde: Knuitershoek & $2016 / 3415$ & Mosselen & $\mathrm{nb}$ & $\mathrm{nb}$ & $\mathrm{nb}$ & $\mathrm{nb}$ & $\mathrm{nb}$ & $\mathrm{nb}$ & $\mathrm{nb}$ & $\mathrm{nb}$ & $\mathrm{nb}$ & $\mathrm{nb}$ \\
\hline
\end{tabular}

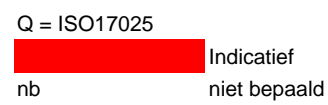


Bijlage 6. Gehalten organotinverbindingen mosselen en oesters in $\mu \mathrm{g} / \mathrm{kg}$ (onderzoek najaar 2016)

\begin{tabular}{|c|c|c|c|c|c|c|c|c|c|}
\hline & & & & $\begin{array}{c}\text { Dibutyltin kation } \\
\mu \mathrm{g} / \mathrm{kg} \\
\mathrm{Q}\end{array}$ & $\begin{array}{c}\text { Diphenyltin kation } \\
\mu \mathrm{g} / \mathrm{kg}\end{array}$ & $\begin{array}{c}\text { Monobutyltin kation } \\
\mu \mathrm{g} / \mathrm{kg}\end{array}$ & $\begin{array}{c}\text { Monophenyltin kation } \\
\mu \mathrm{g} / \mathrm{kg}\end{array}$ & $\begin{array}{c}\text { Tributyltin kation } \\
\mu \mathrm{g} / \mathrm{kg} \\
\mathrm{Q}\end{array}$ & $\begin{array}{c}\text { Triphenyltin kation } \\
\mu \mathrm{g} / \mathrm{kg}\end{array}$ \\
\hline RQ20161128/088 & Eems-Dollard: Bocht van Watum & $2016 / 3420$ & Oesters & $<3.6$ & $<3.8$ & $<3.0$ & $<3.1$ & $<4.1$ & $<4.2$ \\
\hline RQ20161128/088 & Eems-Dollard: Bocht van Watum & $2016 / 3421$ & Oesters & $<4.5$ & $<4.7$ & $<3.8$ & $<3.9$ & $<5.1$ & $<5.2$ \\
\hline RQ20161128/088 & Eems-Dollard: Bocht van Watum & $2016 / 3422$ & Oesters & $<4.3$ & $<4.5$ & $<3.6$ & $<3.7$ & $<4.8$ & $<5.0$ \\
\hline
\end{tabular}

\begin{tabular}{|c|c|c|c|c|c|c|c|c|c|}
\hline & & & & $\begin{array}{c}\text { Dibutyltin kation } \\
\mu \mathrm{g} / \mathrm{kg} \\
\mathrm{Q} \\
\end{array}$ & $\begin{array}{c}\text { Diphenyltin kation } \\
\mu \mathrm{g} / \mathrm{kg}\end{array}$ & $\begin{array}{c}\text { Monobutyltin kation } \\
\mu \mathrm{g} / \mathrm{kg}\end{array}$ & $\begin{array}{c}\text { Monophenyltin kation } \\
\mu \mathrm{g} / \mathrm{kg}\end{array}$ & $\begin{array}{c}\text { Tributyltin kation } \\
\mu \mathrm{g} / \mathrm{kg} \\
\mathrm{Q} \\
\end{array}$ & $\begin{array}{c}\text { Triphenyltin kation } \\
\mu \mathrm{g} / \mathrm{kg}\end{array}$ \\
\hline RQ20161128/089 & Westerschelde: Knuitershoek & $2016 / 3426$ & Oesters & $<3.4$ & $<3.6$ & $<2.9$ & $<3.0$ & $<3.9$ & $<4.0$ \\
\hline RQ20161128/089 & Westerschelde: Knuitershoek & $2016 / 3427$ & Oesters & $<8.2$ & $<8.5$ & $<6.8$ & $<7.1$ & $<9.2$ & $<9.4$ \\
\hline RQ20161128/089 & Westerschelde: Knuitershoek & $2016 / 3428$ & Oesters & $<0.8$ & $<0.8$ & $<0.7$ & $<0.7$ & 5.4 & $<0.9$ \\
\hline
\end{tabular}

\begin{tabular}{|c|c|c|c|c|c|c|c|c|c|}
\hline & & & & $\begin{array}{c}\text { Dibutyltin kation } \\
\mu \mathrm{g} / \mathrm{kg} \\
\mathrm{Q}\end{array}$ & $\begin{array}{c}\text { Diphenyltin kation } \\
\mu \mathrm{g} / \mathrm{kg}\end{array}$ & $\begin{array}{c}\text { Monobutyltin kation } \\
\mu \mathrm{gg} / \mathrm{kg}\end{array}$ & $\begin{array}{c}\text { Monophenyltin kation } \\
\mu \mathrm{gg} / \mathrm{kg}\end{array}$ & $\begin{array}{c}\text { Tributyltin kation } \\
\mu \mathrm{g} / \mathrm{kg} \\
\mathrm{Q}\end{array}$ & $\begin{array}{c}\text { Triphenyltin kation } \\
\mu \mathrm{g} / \mathrm{kg}\end{array}$ \\
\hline RQ20161128/087 & Westerschelde: Knuitershoek & $2016 / 3412$ & Mosselen & 5.1 & $<0.6$ & $<0.5$ & $<0.5$ & 21 & $<0.6$ \\
\hline RQ20161128/087 & Westerschelde: Knuitershoek & $2016 / 3413$ & Mosselen & $<2.8$ & $<3.0$ & $<2.4$ & $<2.5$ & 6.5 & $<3.3$ \\
\hline RQ20161128/087 & Westerschelde: Knuitershoek & $2016 / 3414$ & Mosselen & 1.4 & $<1.3$ & $<1.1$ & $<1.1$ & 12 & $<1.5$ \\
\hline RQ20161128/087 & Westerschelde: Knuitershoek & $2016 / 3415$ & Mosselen & $\mathrm{nb}$ & $\mathrm{nb}$ & $\mathrm{nb}$ & $\mathrm{nb}$ & $\mathrm{nb}$ & $\mathrm{nb}$ \\
\hline RQ20161128/087 & Westerschelde: Knuitershoek & $2016 / 3416$ & Mosselen & $\mathrm{nb}$ & $\mathrm{nb}$ & $\mathrm{nb}$ & $\mathrm{nb}$ & $\mathrm{nb}$ & $\mathrm{nb}$ \\
\hline
\end{tabular}

$\mathrm{nb}=$ niet bepaald 
Bijlage 7. Gehalten perfluorverbindingen mosselen en oesters in $\mu \mathrm{g} / \mathrm{kg}$ (onderzoek najaar 2016'

\begin{tabular}{|c|c|c|c|c|c|c|c|c|c|c|c|}
\hline & & & & $\begin{array}{l}\text { PFBA } \\
\mu g / k g\end{array}$ & $\begin{array}{l}\text { PFBS } \\
\mu \mathrm{g} / \mathrm{kg}\end{array}$ & $\begin{array}{l}\text { PFDcA } \\
\mu \mathrm{g} / \mathrm{kg}\end{array}$ & $\begin{array}{l}\text { PFDoA } \\
\mu \mathrm{g} / \mathrm{kg}\end{array}$ & $\begin{array}{l}\text { PFDS } \\
\mu \mathrm{g} / \mathrm{kg}\end{array}$ & $\begin{array}{c}\text { PFHpA } \\
\mu g / k g\end{array}$ & $\begin{array}{c}\text { PFHpS } \\
\mu \mathrm{g} / \mathrm{kg}\end{array}$ & $\begin{array}{c}\text { PFHxA } \\
\mu g / k g\end{array}$ \\
\hline RQ20161128/088 & Eems-Dollard: Bocht van Watum & $2016 / 3420$ & Oesters & $<1.2$ & $<0.5$ & $<0.3$ & $<0.3$ & $<0.5$ & $<0.3$ & $<0.5$ & $<0.3$ \\
\hline RQ20161128/088 & Eems-Dollard: Bocht van Watum & $2016 / 3421$ & Oesters & $<1.3$ & $<0.5$ & $<0.3$ & $<0.3$ & $<0.5$ & $<0.3$ & $<0.5$ & $<0.3$ \\
\hline \multirow[t]{2}{*}{ RQ20161128/088 } & Eems-Dollard: Bocht van Watum & $2016 / 3422$ & Oesters & $<1.0$ & $<0.4$ & $<0.2$ & $<0.2$ & $<0.4$ & $<0.2$ & $<0.4$ & $<0.2$ \\
\hline & & & & $\begin{array}{l}\text { PFHxS } \\
\mu g / k g\end{array}$ & $\begin{array}{l}\text { PFNA } \\
\mu \mathrm{g} / \mathrm{kg}\end{array}$ & $\begin{array}{c}\text { PFOA } \\
\mu \mathrm{g} / \mathrm{kg} \\
\mathrm{Q}\end{array}$ & $\begin{array}{c}\text { PFOS } \\
\mu \mathrm{g} / \mathrm{kg} \\
\mathrm{Q}\end{array}$ & $\begin{array}{c}\text { PFPeA } \\
\mu \mathrm{g} / \mathrm{kg}\end{array}$ & $\begin{array}{c}\text { PFTeA } \\
\mu \mathrm{g} / \mathrm{kg}\end{array}$ & $\begin{array}{l}\text { PFTrA } \\
\mu g / k g\end{array}$ & $\begin{array}{c}\text { PFUnA } \\
\mu \mathrm{g} / \mathrm{kg}\end{array}$ \\
\hline RQ20161128/088 & Eems-Dollard: Bocht van Watum & $2016 / 3420$ & Oesters & $<0.5$ & $<0.3$ & $<0.3$ & $<0.5$ & $<0.3$ & $<0.6$ & $<0.6$ & $<0.3$ \\
\hline RQ20161128/088 & Eems-Dollard: Bocht van Watum & $2016 / 3421$ & Oesters & $<0.5$ & $<0.3$ & $<0.3$ & $<0.5$ & $<0.3$ & $<0.6$ & $<0.6$ & $<0.3$ \\
\hline RQ20161128/088 & Eems-Dollard: Bocht van Watum & $2016 / 3422$ & Oesters & $<0.4$ & $<0.2$ & $<0.2$ & $<0.4$ & $<0.2$ & $<0.5$ & $<0.5$ & $<0.2$ \\
\hline
\end{tabular}

\begin{tabular}{|c|c|c|c|c|c|c|c|c|c|c|c|}
\hline & & & & $\begin{array}{l}\text { PFBA } \\
\mu g / k g\end{array}$ & $\begin{array}{l}\text { PFBS } \\
\mu g / k g\end{array}$ & $\begin{array}{c}\text { PFDcA } \\
\mu \mathrm{g} / \mathrm{kg}\end{array}$ & $\begin{array}{c}\text { PFDoA } \\
\mu \mathrm{g} / \mathrm{kg}\end{array}$ & $\begin{array}{l}\text { PFDS } \\
\mu g / k g\end{array}$ & $\begin{array}{c}\text { PFHpA } \\
\mu \mathrm{g} / \mathrm{kg}\end{array}$ & $\begin{array}{c}\text { PFHpS } \\
\mu \mathrm{g} / \mathrm{kg}\end{array}$ & $\begin{array}{c}\text { PFHXA } \\
\mu g / k g\end{array}$ \\
\hline RQ20161128/089 & Westerschelde: Knuitershoek & $2016 / 3426$ & Oesters & $<1.1$ & $<0.4$ & $<0.2$ & $<0.2$ & $<0.5$ & $<0.2$ & $<0.5$ & $<0.2$ \\
\hline RQ20161128/089 & Westerschelde: Knuitershoek & $2016 / 3427$ & Oesters & $<1.3$ & $<0.5$ & $<0.3$ & $<0.3$ & $<0.5$ & $<0.3$ & $<0.5$ & $<0.3$ \\
\hline RQ20161128/089 & Westerschelde: Knuitershoek & $2016 / 3428$ & Oesters & $<1.2$ & $<0.5$ & $<0.3$ & $<0.3$ & $<0.5$ & $<0.3$ & $<0.5$ & $<0.3$ \\
\hline
\end{tabular}

\begin{tabular}{|c|c|c|c|c|c|c|c|c|c|c|c|}
\hline & & & & $\begin{array}{c}\text { PFHxS } \\
\mu g / k g\end{array}$ & $\begin{array}{l}\text { PFNA } \\
\mu \mathrm{g} / \mathrm{kg}\end{array}$ & $\begin{array}{c}\text { PFOA } \\
\mu g / k g \\
Q\end{array}$ & $\begin{array}{c}\text { PFOS } \\
\mu \mathrm{g} / \mathrm{kg} \\
\mathrm{Q}\end{array}$ & $\begin{array}{c}\text { PFPeA } \\
\mu \mathrm{g} / \mathrm{kg}\end{array}$ & $\begin{array}{c}\text { PFTeA } \\
\mu \mathrm{g} / \mathrm{kg}\end{array}$ & $\begin{array}{l}\text { PFTrA } \\
\mu \mathrm{g} / \mathrm{kg}\end{array}$ & $\begin{array}{c}\text { PFUnA } \\
\mu \mathrm{g} / \mathrm{kg}\end{array}$ \\
\hline RQ20161128/089 & Westerschelde: Knuitershoek & $2016 / 3426$ & Oesters & $<0.5$ & $<0.2$ & $<0.2$ & $<0.5$ & $<0.2$ & $<0.5$ & $<0.5$ & $<0.2$ \\
\hline RQ20161128/089 & Westerschelde: Knuitershoek & $2016 / 3427$ & Oesters & $<0.5$ & $<0.3$ & $<0.3$ & $<0.5$ & $<0.3$ & $<0.6$ & $<0.6$ & $<0.3$ \\
\hline RQ20161128/089 & Westerschelde: Knuitershoek & $2016 / 3428$ & Oesters & $<0.5$ & $<0.3$ & $<0.3$ & $<0.5$ & $<0.3$ & $<0.5$ & $<0.5$ & $<0.3$ \\
\hline
\end{tabular}

\begin{tabular}{|c|c|c|c|c|c|c|c|c|c|c|c|}
\hline & & & & $\begin{array}{l}\text { PFBA } \\
\mu g / k g\end{array}$ & $\begin{array}{l}\text { PFBS } \\
\mu g / k g\end{array}$ & $\begin{array}{l}\text { PFDcA } \\
\mu \mathrm{g} / \mathrm{kg}\end{array}$ & $\begin{array}{l}\text { PFDoA } \\
\mu g / k g\end{array}$ & $\begin{array}{l}\text { PFDS } \\
\mu g / k g\end{array}$ & $\begin{array}{c}\text { PFHpA } \\
\mu \mathrm{g} / \mathrm{kg}\end{array}$ & $\begin{array}{l}\text { PFHpS } \\
\mu g / k g\end{array}$ & $\begin{array}{c}\text { PFHxA } \\
\mu g / k g\end{array}$ \\
\hline RQ20161128/087 & Westerschelde: Knuitershoek & $2016 / 3412$ & Mosselen & $<1.3$ & $<0.5$ & $<0.3$ & $<0.3$ & $<0.6$ & $<0.3$ & $<0.6$ & $<0.3$ \\
\hline RQ20161128/087 & Westerschelde: Knuitershoek & $2016 / 3413$ & Mosselen & $<1.5$ & $<0.6$ & $<0.3$ & $<0.3$ & $<0.6$ & $<0.3$ & $<0.6$ & $<0.3$ \\
\hline RQ20161128/087 & Westerschelde: Knuitershoek & $2016 / 3414$ & Mosselen & $<1.4$ & $<0.5$ & $<0.3$ & $<0.3$ & $<0.6$ & $<0.3$ & $<0.6$ & $<0.3$ \\
\hline RQ20161128/087 & Westerschelde: Knuitershoek & $2016 / 3415$ & Mosselen & $\mathrm{nb}$ & $\mathrm{nb}$ & $\mathrm{nb}$ & $\mathrm{nb}$ & $\mathrm{nb}$ & $\mathrm{nb}$ & $\mathrm{nb}$ & $\mathrm{nb}$ \\
\hline RQ20161128/087 & Westerschelde: Knuitershoek & 2016/3416 & Mosselen & $\mathrm{nb}$ & $\mathrm{nb}$ & $\mathrm{nb}$ & $\mathrm{nb}$ & $\mathrm{nb}$ & $\mathrm{nb}$ & $\mathrm{nb}$ & $\mathrm{nb}$ \\
\hline
\end{tabular}

\begin{tabular}{|c|c|c|c|c|c|c|c|c|c|c|c|}
\hline & & & & $\begin{array}{c}\text { PFHxS } \\
\mu g / k g\end{array}$ & $\begin{array}{l}\text { PFNA } \\
\mu g / k g\end{array}$ & $\begin{array}{c}\text { PFOA } \\
\mu g / k g \\
Q\end{array}$ & $\begin{array}{c}\text { PFOS } \\
\mu g / k g \\
Q\end{array}$ & $\begin{array}{c}\text { PFPeA } \\
\mu \mathrm{g} / \mathrm{kg}\end{array}$ & $\begin{array}{c}\text { PFTeA } \\
\mu \mathrm{g} / \mathrm{kg}\end{array}$ & $\begin{array}{c}\text { PFTrA } \\
\mu \mathrm{g} / \mathrm{kg}\end{array}$ & $\begin{array}{r}\text { PFUnA } \\
\mu \mathrm{g} / \mathrm{kg}\end{array}$ \\
\hline RQ20161128/087 & Westerschelde: Knuitershoek & 2016/3412 & Mosselen & $<0.6$ & $<0.3$ & $<0.3$ & $<0.6$ & $<0.3$ & $<0.6$ & $<0.6$ & $<0.3$ \\
\hline RQ20161128/087 & Westerschelde: Knuitershoek & $2016 / 3413$ & Mosselen & $<0.6$ & $<0.3$ & $<0.3$ & $<0.6$ & $<0.3$ & $<0.7$ & $<0.7$ & $<0.3$ \\
\hline RQ20161128/087 & Westerschelde: Knuitershoek & $2016 / 3414$ & Mosselen & $<0.6$ & $<0.3$ & $<0.3$ & $<0.6$ & $<0.3$ & $<0.6$ & $<0.6$ & $<0.3$ \\
\hline RQ20161128/087 & Westerschelde: Knuitershoek & $2016 / 3415$ & Mosselen & $\mathrm{nb}$ & $\mathrm{nb}$ & $\mathrm{nb}$ & $\mathrm{nb}$ & $\mathrm{nb}$ & $\mathrm{nb}$ & $\mathrm{nb}$ & $\mathrm{nb}$ \\
\hline RQ20161128/087 & Westerschelde: Knuitershoek & 2016/3416 & Mosselen & $\mathrm{nb}$ & $\mathrm{nb}$ & $\mathrm{nb}$ & $\mathrm{nb}$ & $\mathrm{nb}$ & $\mathrm{nb}$ & $\mathrm{nb}$ & $\mathrm{nb}$ \\
\hline
\end{tabular}

\section{$\mathrm{Q}=\mathrm{ISO} 17025$}

$\mathrm{nb}=$ niet bepaald 
Resultaten referentiematerialen

\begin{tabular}{|c|c|c|c|c|c|c|c|c|c|}
\hline Component & Referentiemateriaal & $\begin{array}{c}\text { IMARES-waarde } \\
\text { in } 2016 \\
\end{array}$ & $\begin{array}{c}n \\
\text { in } 2016 \\
\end{array}$ & $\begin{array}{c}\text { IMARES-waarde } \\
\text { QC-kaart }\end{array}$ & $\begin{array}{c}\mathrm{n} \\
\text { totaal }\end{array}$ & ng/dg & $\begin{array}{c}\text { gecertificeerde } \\
\text { waarde }\end{array}$ & eenheid & kwalificatie \\
\hline PBDE28 & IRM 2014/004 aal & $0.33 \pm 0.01$ & 3 & $0.29 \pm 0.03$ & 14 & $\mathrm{ng}$ & n.v.t. & $\mu \mathrm{g} / \mathrm{kg}$ & geen \\
\hline PBDE47 & IRM 2014/004 aal & $22.0 \pm 2.1$ & 3 & $21.9 \pm 1.8$ & 13 & $\mathrm{ng}$ & n.v.t. & $\mu \mathrm{g} / \mathrm{kg}$ & geen \\
\hline PBDE99 & IRM 2014/004 aal & $1.10 \pm 0.026$ & 3 & $1.10 \pm 0.07$ & 14 & $\mathrm{ng}$ & n.v.t. & $\mu \mathrm{g} / \mathrm{kg}$ & geen \\
\hline PBDE100 & IRM 2014/004 aal & $8.0 \pm 0.35$ & 3 & $8.6 \pm 0.86$ & 14 & $\mathrm{ng}$ & n.v.t. & $\mu \mathrm{g} / \mathrm{kg}$ & geen \\
\hline PBDE119 & IRM 2014/004 aal & $0.141 \pm 0.0045$ & 2 & $0.13 \pm 0.039$ & 10 & $\mathrm{ng}$ & n.v.t. & $\mu \mathrm{g} / \mathrm{kg}$ & geen \\
\hline PBDE153 & IRM 2014/004 aal & $1.04 \pm 0.037$ & 3 & $1.06 \pm 0.07$ & 14 & $\mathrm{ng}$ & n.v.t. & $\mu \mathrm{g} / \mathrm{kg}$ & geen \\
\hline PBDE154 & IRM 2014/004 aal & $1.02 \pm 0.04$ & 3 & $0.97 \pm 0.09$ & 12 & $\mathrm{ng}$ & n.v.t. & $\mu \mathrm{g} / \mathrm{kg}$ & geen \\
\hline HBCD & IRM 2014/004 aal & $26.1 \pm 0.7$ & 3 & $26.7 \pm 2.9$ & 12 & $\mathrm{ng}$ & n.v.t. & $\mu \mathrm{g} / \mathrm{kg}$ & geen \\
\hline PFBA & IRM snoekbaars filer 1e interlab & $46.7 \pm 2.2$ & 5 & $49.9 \pm 4.1$ & 34 & $\mathrm{ng}$ & n.v.t. & $\mu \mathrm{g} / \mathrm{kg}$ & goed \\
\hline PFBS & IRM snoekbaars filer $1 \mathrm{e}$ interlab & $18.2 \pm 1.2$ & 6 & $19.8 \pm 2.3$ & 44 & $\mathrm{ng}$ & n.v.t. & $\mu \mathrm{g} / \mathrm{kg}$ & goed \\
\hline PFDcA & IRM snoekbaars filer 1e interlab & $2.9 \pm 0.28$ & 7 & $2.4 \pm 0.27$ & 20 & $\mathrm{ng}$ & n.v.t. & $\mu \mathrm{g} / \mathrm{kg}$ & goed \\
\hline PFDoA & IRM snoekbaars filer 1e interlab & $40.9 \pm 3.7$ & 5 & $40.4 \pm 6.0$ & 32 & $\mathrm{ng}$ & n.v.t. & $\mu \mathrm{g} / \mathrm{kg}$ & goed \\
\hline PFHXS & IRM snoekbaars filer 1e interlab & $20.1 \pm 1.7$ & 6 & $22.3 \pm 2.3$ & 43 & $\mathrm{ng}$ & n.v.t. & $\mu \mathrm{g} / \mathrm{kg}$ & goed \\
\hline PFNA & IRM snoekbaars filer 1e interlab & $1.5 \pm 0.40$ & 5 & $1.3 \pm 0.56$ & 36 & $\mathrm{ng}$ & n.v.t. & $\mu \mathrm{g} / \mathrm{kg}$ & goed \\
\hline PFOA & IRM snoekbaars filer $1 \mathrm{e}$ interlab & $10.4 \pm 0.73$ & 6 & $9.7 \pm 0.87$ & 49 & $\mathrm{ng}$ & n.v.t. & $\mu \mathrm{g} / \mathrm{kg}$ & goed \\
\hline PFOS & IRM snoekbaars filer 1e interlab & $78.9 \pm 1.6$ & 6 & $78.4 \pm 4.28$ & 61 & $\mathrm{ng}$ & n.v.t. & $\mu \mathrm{g} / \mathrm{kg}$ & goed \\
\hline DBT kation & CRM Mossel CE-477 & $1381 \pm 67.7$ & 2 & $1406 \pm 155$ & 36 & $\mathrm{ng}$ & $1540 \pm 120$ & $\mu \mathrm{g} / \mathrm{kg}$ & goed \\
\hline MBT kation & CRM Mossel CE-477 & $1553 \pm 141$ & 2 & $1540 \pm 192$ & 36 & $\mathrm{ng}$ & $1500 \pm 280$ & $\mu \mathrm{g} / \mathrm{kg}$ & goed \\
\hline TBT kation & CRM Mossel CE-477 & $2297 \pm 146$ & 2 & $2195 \pm 202$ & 36 & $\mathrm{ng}$ & $2200 \pm 190$ & $\mu \mathrm{g} / \mathrm{kg}$ & goed \\
\hline PCB77 & IRM36715 & 23.7 & 1 & $21.5 \pm 5.8$ & 31 & $\mathrm{ng}$ & n.v.t. & $\mu \mathrm{g} / \mathrm{kg}$ & goed \\
\hline PCB126 & IRM36715 & 122.1 & 1 & $107 \pm 16.9$ & 34 & $\mathrm{ng}$ & n.v.t. & $\mu \mathrm{g} / \mathrm{kg}$ & goed \\
\hline PCB169 & IRM36715 & 18.8 & 1 & $19.0 \pm 2.18$ & 35 & $\mathrm{ng}$ & n.v.t. & $\mu \mathrm{g} / \mathrm{kg}$ & goed \\
\hline Kwik & IRM Schol 2004/2069 & $0.0575 \pm 0.0029$ & 6 & $0.0585 \pm 0.0030$ & 40 & $\mathrm{ng}$ & n.v.t. & $\mathrm{mg} / \mathrm{kg}$ & goed \\
\hline Kwik & Oyster Tissue NIST1566b & $0.0386 \pm 0.0011$ & 6 & $0.0377 \pm 0.0017$ & 57 & $\mathrm{dg}$ & $0.0371 \pm 0.0013$ & $\mathrm{mg} / \mathrm{kg}$ & goed \\
\hline Dry-weight & IRM 2005/0775 Haring/makreel & $70.08 \pm 0.18$ & 9 & $70.00 \pm 0.252$ & 245 & $\mathrm{ng}$ & n.v.t. & $\%$ & goed \\
\hline Ash-Weight & IRM 2002/0757 Mosselen & $1.57 \pm 0.02$ & 3 & $1.58 \pm 0.04$ & 83 & $\mathrm{ng}$ & n.v.t. & $\%$ & goed \\
\hline Total-Lipid & IRM 2005/0775 Haring/makreel & $11.49 \pm 0.12$ & 16 & $11.54 \pm 0.14$ & 183 & $\mathrm{ng}$ & n.v.t. & $\%$ & goed \\
\hline CB28 & IRM 2014/004 aal & $6.16 \pm 0.57$ & 10 & $6.01 \pm 0.63$ & 12 & $\mathrm{ng}$ & n.v.t. & $\mu \mathrm{g} / \mathrm{kg}$ & geen \\
\hline CB52 & IRM 2014/004 aal & $47.0 \pm 1.9$ & 10 & $47.0 \pm 1.9$ & 12 & $\mathrm{ng}$ & n.v.t. & $\mu \mathrm{g} / \mathrm{kg}$ & geen \\
\hline CB49 & IRM 2014/004 aal & $12.2 \pm 0.5$ & 9 & $12.1 \pm 0.5$ & 11 & $\mathrm{ng}$ & n.v.t. & $\mu \mathrm{g} / \mathrm{kg}$ & geen \\
\hline CB66 & IRM 2014/004 aal & $20.1 \pm 0.6$ & 9 & $20.1 \pm 0.5$ & 11 & $\mathrm{ng}$ & n.v.t. & $\mu \mathrm{g} / \mathrm{kg}$ & geen \\
\hline CB101 & IRM 2014/004 aal & $74.4 \pm 3.2$ & 10 & $75.2 \pm 3.4$ & 12 & $\mathrm{ng}$ & n.v.t. & $\mu \mathrm{g} / \mathrm{kg}$ & geen \\
\hline CB97 & IRM 2014/004 aal & $16.5 \pm 0.4$ & 9 & $16.6 \pm 0.5$ & 11 & $\mathrm{ng}$ & n.v.t. & $\mu \mathrm{g} / \mathrm{kg}$ & geen \\
\hline CB87 & IRM 2014/004 aal & $9.87 \pm 0.37$ & 9 & $9.96 \pm 0.39$ & 11 & $\mathrm{ng}$ & n.v.t. & $\mu \mathrm{g} / \mathrm{kg}$ & geen \\
\hline CB85 & IRM 2014/004 aal & $9.08 \pm 0.46$ & 9 & $9.09 \pm 0.42$ & 11 & $\mathrm{ng}$ & n.v.t. & $\mu \mathrm{g} / \mathrm{kg}$ & geen \\
\hline CB110 & IRM 2014/004 aal & $71.7 \pm 3.4$ & 9 & $71.8 \pm 3.1$ & 11 & $\mathrm{ng}$ & n.v.t. & $\mu \mathrm{g} / \mathrm{kg}$ & geen \\
\hline CB151 & IRM 2014/004 aal & $27.0 \pm 1.6$ & 9 & $27.4 \pm 1.7$ & 12 & $\mathrm{ng}$ & n.v.t. & $\mu \mathrm{g} / \mathrm{kg}$ & geen \\
\hline CB149 & IRM 2014/004 aal & $119 \pm 7$ & 10 & $119 \pm 6$ & 12 & $\mathrm{ng}$ & n.v.t. & $\mu \mathrm{g} / \mathrm{kg}$ & geen \\
\hline CB118 & IRM 2014/004 aal & $76.1 \pm 1.8$ & 9 & $76.7 \pm 2.1$ & 12 & $\mathrm{ng}$ & n.v.t. & $\mu \mathrm{g} / \mathrm{kg}$ & geen \\
\hline CB153 & IRM 2014/004 aal & $313 \pm 22$ & 10 & $317 \pm 21$ & 12 & $\mathrm{ng}$ & n.v.t. & $\mu \mathrm{g} / \mathrm{kg}$ & geen \\
\hline CB141 & IRM 2014/004 aal & $15.7 \pm 1.1$ & 9 & $15.8 \pm 1.1$ & 11 & $\mathrm{ng}$ & n.v.t. & $\mu \mathrm{g} / \mathrm{kg}$ & geen \\
\hline CB105 & IRM 2014/004 aal & $13.9 \pm 0.6$ & 10 & $14.0 \pm 0.7$ & 12 & $\mathrm{ng}$ & n.v.t. & $\mu \mathrm{g} / \mathrm{kg}$ & geen \\
\hline CB138 & IRM 2014/004 aal & $150.7 \pm 8.6$ & 10 & $152.1 \pm 8.5$ & 12 & $\mathrm{ng}$ & n.v.t. & $\mu \mathrm{g} / \mathrm{kg}$ & geen \\
\hline CB187 & IRM 2014/004 aal & $87.6 \pm 3.1$ & 8 & $89.0 \pm 4.1$ & 10 & $\mathrm{ng}$ & n.v.t. & $\mu \mathrm{g} / \mathrm{kg}$ & geen \\
\hline CB128 & IRM 2014/004 aal & $22.1 \pm 1.2$ & 8 & $22.2 \pm 1.1$ & 10 & $\mathrm{ng}$ & n.v.t. & $\mu \mathrm{g} / \mathrm{kg}$ & geen \\
\hline CB156 & IRM 2014/004 aal & $10.1 \pm 1.1$ & 11 & $10.2 \pm 1.0$ & 13 & $\mathrm{ng}$ & n.v.t. & $\mu \mathrm{g} / \mathrm{kg}$ & geen \\
\hline CB180 & IRM 2014/004 aal & $88.8 \pm 6.2$ & 10 & $88.5 \pm 5.7$ & 12 & $\mathrm{ng}$ & n.v.t. & $\mu \mathrm{g} / \mathrm{kg}$ & geen \\
\hline CB170 & IRM 2014/004 aal & $27.9 \pm 1.3$ & 9 & $28.0 \pm 1.2$ & 11 & $\mathrm{ng}$ & n.v.t. & $\mu \mathrm{g} / \mathrm{kg}$ & geen \\
\hline $\mathrm{HCBD}$ & IRM 2014/004 aal & $6.52 \pm 0.57$ & 11 & $6.61 \pm 0.56$ & 13 & $\mathrm{ng}$ & n.v.t. & $\mu \mathrm{g} / \mathrm{kg}$ & geen \\
\hline $\mathrm{HCB}$ & IRM 2014/004 aal & $15.6 \pm 1.7$ & 12 & $15.5 \pm 1.5$ & 15 & $\mathrm{ng}$ & n.v.t. & $\mu \mathrm{g} / \mathrm{kg}$ & geen \\
\hline Pyreen & IRM 682 & 28 & 1 & $26.4 \pm 2.74$ & 16 & $\mathrm{ng}$ & n.v.t. & $\mu \mathrm{g} / \mathrm{kg}$ & goed \\
\hline Fluoranteen & IRM 682 & 35 & 1 & $36.3 \pm 2.59$ & 15 & $\mathrm{ng}$ & n.v.t. & $\mu \mathrm{g} / \mathrm{kg}$ & goed \\
\hline Benzo(b)fluoranteen & IRM 682 & 12 & 1 & $13.5 \pm 2.06$ & 16 & $\mathrm{ng}$ & n.v.t. & $\mu \mathrm{g} / \mathrm{kg}$ & goed \\
\hline Benzo(ghi)peryleen & IRM 682 & 7.5 & 1 & $6.1 \pm 0.99$ & 16 & $\mathrm{ng}$ & n.v.t. & $\mu \mathrm{g} / \mathrm{kg}$ & goed \\
\hline Indeno(1,2,3-cd)pyreen & IRM 682 & 7.3 & 1 & $6.9 \pm 0.85$ & 15 & $\mathrm{ng}$ & n.v.t. & $\mu \mathrm{g} / \mathrm{kg}$ & goed \\
\hline
\end{tabular}

\begin{tabular}{|c|c|c|c|c|c|c|c|c|c|}
\hline Component & Referentiemateriaal & TNO-waarde & $\begin{array}{c}n \\
\text { in } 2014\end{array}$ & $\begin{array}{c}\text { IMARES-waarde } \\
\text { QC-kaart }\end{array}$ & $\begin{array}{c}\mathrm{n} \\
\text { totaal }\end{array}$ & ng/dg & $\begin{array}{c}\text { gecertificeerde } \\
\text { waarde }\end{array}$ & eenheid & kwalificatie \\
\hline Cadmium & IRM LAC schol geen nr. & 0.029 & 5 & $0.020 \pm 0.009$ & 147 & $\mathrm{dg}$ & $0.020 \pm 0.005$ & $\mathrm{mg} / \mathrm{kg}$ & goed \\
\hline Zink & IRM LAC schol geen nr. & 26.5 & 1 & $26.6 \pm 2.1$ & 104 & $\mathrm{dg}$ & $26.6 \pm 1.7$ & $\mathrm{mg} / \mathrm{kg}$ & goed \\
\hline Koper & IRM LAC schol geen $\mathrm{nr}$. & 0.97 & 6 & $1.04 \pm 0.11$ & 95 & $\mathrm{dg}$ & $1.11 \pm 0.25$ & $\mathrm{mg} / \mathrm{kg}$ & goed \\
\hline Lood & IRM LAC schol geen nr. & 1.72 & 6 & $1.56 \pm 0.30$ & 107 & $\mathrm{dg}$ & $1.55 \pm 0.05$ & $\mathrm{mg} / \mathrm{kg}$ & goed \\
\hline Chroom & IRM LAC schol geen nr. & 0.072 & 1 & niet bepaald & 0 & $\mathrm{dg}$ & onbekend & $\mathrm{mg} / \mathrm{kg}$ & n.v.t. \\
\hline Nikkel & IRM LAC schol geen nr. & 0.29 & 1 & niet bepaald & 0 & $\mathrm{dg}$ & $0.29 \pm 0.10$ & $\mathrm{mg} / \mathrm{kg}$ & goed \\
\hline Arseen & IRM LAC schol geen nr. & 62 & 6 & $67.23 \pm 8.30$ & 150 & $\mathrm{dg}$ & $62.1 \pm 3.7$ & $\mathrm{mg} / \mathrm{kg}$ & goed \\
\hline
\end{tabular}


labcode: Q127 IMARES

\begin{tabular}{|c|c|c|c|c|c|c|c|c|c|}
\hline Group & Round & Period & Matrix & Determinand & Unit & Z-score & Qualification & Comment & accreditatie \\
\hline BT10 & 2016.01 & jan 2016 & QPF004BT & PFOS & $\mu \mathrm{g} / \mathrm{kg}$ & -0.3 & Satisfactory & Quasimeme & ja \\
\hline BT1 & 2016.01 & april 2016 & QTM109BT & Dry-weight & $\%$ & -0.3 & Satisfactory & Quasimeme & ja \\
\hline BT1 & 2016.01 & april 2016 & QTM110BT & Dry-weight & $\%$ & 0.0 & Satisfactory & Quasimeme & ja \\
\hline BT1 & 2016.02 & nov 2016 & QTM112BT & Dry-weight & $\%$ & 0.0 & Satisfactory & Quasimeme & ja \\
\hline BT1 & 2016.02 & nov 2016 & QTM113BT & Dry-weight & $\%$ & -0.2 & Satisfactory & Quasimeme & ja \\
\hline BT1 & 2016.01 & april 2016 & QTM110BT & Ash-Weight & $\%$ & -0.3 & Satisfactory & Quasimeme & ja \\
\hline BT1 & 2016.01 & april 2016 & QTM110BT & Total-Lipid & $\%$ & -0.1 & Satisfactory & Quasimeme & ja \\
\hline BT1 & 2016.02 & nov 2016 & QTM112BT & Total-Lipid & $\%$ & 0.0 & Satisfactory & Quasimeme & ja \\
\hline BT9 & 2016.01 & april 2016 & QBC046BT & BDE100 & $\mu \mathrm{g} / \mathrm{kg}$ & 0.1 & Satisfactory & Quasimeme & ja \\
\hline BT9 & 2016.01 & april 2016 & QBC047BT & BDE100 & $\mu \mathrm{g} / \mathrm{kg}$ & -1.1 & Satisfactory & Quasimeme & ja \\
\hline BT9 & 2016.01 & april 2016 & QBC046BT & BDE153 & $\mu \mathrm{g} / \mathrm{kg}$ & 0.0 & Satisfactory & Quasimeme & ja \\
\hline BT9 & 2016.01 & april 2016 & QBC047BT & BDE153 & $\mu \mathrm{g} / \mathrm{kg}$ & 2.0 & Satisfactory & Quasimeme & ja \\
\hline BT9 & 2016.01 & april 2016 & QBC046BT & BDE154 & $\mu \mathrm{g} / \mathrm{kg}$ & -0.4 & Satisfactory & Quasimeme & ja \\
\hline BT9 & 2016.01 & april 2016 & QBC047BT & BDE154 & $\mu \mathrm{g} / \mathrm{kg}$ & -0.9 & Satisfactory & Quasimeme & ja \\
\hline BT9 & 2016.01 & april 2016 & QBC047BT & BDE183 & $\mu \mathrm{g} / \mathrm{kg}$ & -2.0 & Satisfactory & Quasimeme & nee \\
\hline BT9 & 2016.01 & april 2016 & QBC046BT & BDE28 & $\mu \mathrm{g} / \mathrm{kg}$ & 0.0 & Satisfactory & Quasimeme & ja \\
\hline BT9 & 2016.01 & april 2016 & QBC047BT & BDE28 & $\mu \mathrm{g} / \mathrm{kg}$ & -0.3 & Satisfactory & Quasimeme & ja \\
\hline BT9 & 2016.01 & april 2016 & QBC046BT & BDE47 & $\mu \mathrm{g} / \mathrm{kg}$ & -0.1 & Satisfactory & Quasimeme & ja \\
\hline BT9 & 2016.01 & april 2016 & QBC047BT & BDE47 & $\mu \mathrm{g} / \mathrm{kg}$ & -1.0 & Satisfactory & Quasimeme & ja \\
\hline BT9 & 2016.01 & april 2016 & QBC047BT & BDE66 & $\mu \mathrm{g} / \mathrm{kg}$ & -1.5 & Satisfactory & Quasimeme & ja \\
\hline BT9 & 2016.01 & april 2016 & QBC047BT & BDE85 & $\mu \mathrm{g} / \mathrm{kg}$ & -0.6 & Satisfactory & Quasimeme & ja \\
\hline BT9 & 2016.01 & april 2016 & QBC046BT & BDE99 & $\mu \mathrm{g} / \mathrm{kg}$ & 1.6 & Satisfactory & Quasimeme & ja \\
\hline BT9 & 2016.01 & april 2016 & QBC047BT & BDE99 & $\mu \mathrm{g} / \mathrm{kg}$ & -0.7 & Satisfactory & Quasimeme & ja \\
\hline BT8 & 2016.02 & nov 2016 & QSP058BT & DBT & $\mu \mathrm{g} \mathrm{Sn} / \mathrm{kg}$ & 0.4 & Satisfactory & Quasimeme & ja \\
\hline BT8 & 2016.02 & nov 2016 & QSP059BT & DBT & $\mu \mathrm{g} \mathrm{Sn} / \mathrm{kg}$ & 1.0 & Satisfactory & Quasimeme & ja \\
\hline BT8 & 2016.02 & nov 2016 & QSP058BT & MBT & $\mu \mathrm{g} \mathrm{Sn} / \mathrm{kg}$ & -1.1 & Satisfactory & Quasimeme & nee \\
\hline BT8 & 2016.02 & nov 2016 & QSP059BT & MBT & $\mu \mathrm{g} \mathrm{Sn} / \mathrm{kg}$ & -0.6 & Satisfactory & Quasimeme & nee \\
\hline BT1 & 2016.02 & nov 2016 & QTM112BT & Kwik & $\mu \mathrm{g} / \mathrm{kg}$ & 1.9 & Satisfactory & Quasimeme & ja \\
\hline BT1 & 2016.02 & nov 2016 & QTM113BT & Kwik & $\mu \mathrm{g} / \mathrm{kg}$ & 1.1 & Satisfactory & Quasimeme & ja \\
\hline BT2 & 2015.02 & nov 2015 & QOR124BT & CB31 & $\mu \mathrm{g} / \mathrm{kg}$ & 0.21 & Satisfactory & Quasimeme & ja \\
\hline BT2 & 2015.02 & nov 2015 & QOR124BT & CB28 & $\mu \mathrm{g} / \mathrm{kg}$ & 0.25 & Satisfactory & Quasimeme & ja \\
\hline BT2 & 2015.02 & nov 2015 & QOR124BT & CB52 & $\mu \mathrm{g} / \mathrm{kg}$ & 0.23 & Satisfactory & Quasimeme & ja \\
\hline BT2 & 2015.02 & nov 2015 & QOR125BT & CB52 & $\mu \mathrm{g} / \mathrm{kg}$ & 0.81 & Satisfactory & Quasimeme & ja \\
\hline BT2 & 2015.02 & nov 2015 & QOR124BT & CB101 & $\mu \mathrm{g} / \mathrm{kg}$ & -0.3 & Satisfactory & Quasimeme & ja \\
\hline BT2 & 2015.02 & nov 2015 & QOR125BT & CB101 & $\mu \mathrm{g} / \mathrm{kg}$ & -0.11 & Satisfactory & Quasimeme & ja \\
\hline BT2 & 2015.02 & nov 2015 & QOR124BT & CB118 & $\mu \mathrm{g} / \mathrm{kg}$ & -0.58 & Satisfactory & Quasimeme & ja \\
\hline BT2 & 2015.02 & nov 2015 & QOR125BT & CB118 & $\mu \mathrm{g} / \mathrm{kg}$ & -0.27 & Satisfactory & Quasimeme & ja \\
\hline BT2 & 2015.02 & nov 2015 & QOR124BT & CB153 & $\mu \mathrm{g} / \mathrm{kg}$ & -0.17 & Satisfactory & Quasimeme & ja \\
\hline BT2 & 2015.02 & nov 2015 & QOR125BT & CB153 & $\mu \mathrm{g} / \mathrm{kg}$ & 0.01 & Satisfactory & Quasimeme & ja \\
\hline BT2 & 2015.02 & nov 2015 & QOR124BT & CB105 & $\mu \mathrm{g} / \mathrm{kg}$ & -0.29 & Satisfactory & Quasimeme & ja \\
\hline BT2 & 2015.02 & nov 2015 & QOR125BT & CB105 & $\mu \mathrm{g} / \mathrm{kg}$ & 0.15 & Satisfactory & Quasimeme & ja \\
\hline BT2 & 2015.02 & nov 2015 & QOR124BT & CB138 & $\mu \mathrm{g} / \mathrm{kg}$ & -0.96 & Satisfactory & Quasimeme & ja \\
\hline BT2 & 2015.02 & nov 2015 & QOR125BT & CB138 & $\mu \mathrm{g} / \mathrm{kg}$ & -0.73 & Satisfactory & Quasimeme & ja \\
\hline BT2 & 2015.02 & nov 2015 & QOR124BT & CB156 & $\mu \mathrm{g} / \mathrm{kg}$ & -1.13 & Satisfactory & Quasimeme & ja \\
\hline BT2 & 2015.02 & nov 2015 & QOR125BT & CB156 & $\mu \mathrm{g} / \mathrm{kg}$ & -1.76 & Satisfactory & Quasimeme & ja \\
\hline BT2 & 2015.02 & nov 2015 & QOR124BT & CB180 & $\mu \mathrm{g} / \mathrm{kg}$ & -0.85 & Satisfactory & Quasimeme & ja \\
\hline BT2 & 2015.02 & nov 2015 & QOR125BT & CB180 & $\mu \mathrm{g} / \mathrm{kg}$ & -0.6 & Satisfactory & Quasimeme & ja \\
\hline BT2 & 2015.02 & nov 2015 & QOR125BT & HCB & $\mu \mathrm{g} / \mathrm{kg}$ & 0.48 & Satisfactory & Quasimeme & ja \\
\hline BT2 & 2015.02 & nov 2015 & QOR124BT & $\mathrm{HCB}$ & $\mu \mathrm{g} / \mathrm{kg}$ & 0.61 & Satisfactory & Quasimeme & ja \\
\hline BT4 & 2016.02 & nov 2016 & QPH083BT & Acenafteen & $\mu \mathrm{g} / \mathrm{kg}$ & 1.1 & Satisfactory & Quasimeme & ja \\
\hline BT4 & 2016.02 & nov 2016 & QPH083BT & Fluoreen & $\mu \mathrm{g} / \mathrm{kg}$ & 0.6 & Satisfactory & Quasimeme & ja \\
\hline BT4 & 2016.02 & nov 2016 & QPH084BT & Fluoreen & $\mu \mathrm{g} / \mathrm{kg}$ & 0.8 & Satisfactory & Quasimeme & ja \\
\hline BT4 & 2016.02 & nov 2016 & QPH083BT & Fenantreen & $\mu \mathrm{g} / \mathrm{kg}$ & 2.2 & Questionable & Quasimeme & ja \\
\hline BT4 & 2016.02 & nov 2016 & QPH084BT & Fenantreen & $\mu \mathrm{g} / \mathrm{kg}$ & 2.2 & Questionable & Quasimeme & ja \\
\hline BT4 & 2016.02 & nov 2016 & QPH083BT & Antraceen & $\mu \mathrm{g} / \mathrm{kg}$ & 1.4 & Satisfactory & Quasimeme & ja \\
\hline \begin{tabular}{|l|} 
BT4 \\
\end{tabular} & 2016.02 & nov 2016 & QPH084BT & Antraceen & $\mu \mathrm{g} / \mathrm{kg}$ & 2 & Satisfactory & Quasimeme & ja \\
\hline BT4 & 2016.02 & nov 2016 & QPH083BT & Fluoranteen & $\mu \mathrm{g} / \mathrm{kg}$ & 1.1 & Satisfactory & Quasimeme & ja \\
\hline BT4 & 2016.02 & nov 2016 & QPH084BT & Fluoranteen & $\mu \mathrm{g} / \mathrm{kg}$ & 0.9 & Satisfactory & Quasimeme & ja \\
\hline BT4 & 2016.02 & nov 2016 & QPH083BT & Pyreen & $\mu \mathrm{g} / \mathrm{kg}$ & 2.1 & Questionable & Quasimeme & ja \\
\hline BT4 & 2016.02 & nov 2016 & QPH084BT & Pyreen & $\mu \mathrm{g} / \mathrm{kg}$ & 1.6 & Satisfactory & Quasimeme & ja \\
\hline BT4 & 2016.02 & nov 2016 & QPH083BT & Benzo(a)antraceen & $\mu \mathrm{g} / \mathrm{kg}$ & 1.7 & Satisfactory & Quasimeme & ja \\
\hline BT4 & 2016.02 & nov 2016 & QPH084BT & Benzo(a)antraceen & $\mu \mathrm{g} / \mathrm{kg}$ & 2 & Satisfactory & Quasimeme & ja \\
\hline BT4 & 2016.02 & nov 2016 & QPH083BT & Chryseen & $\mu \mathrm{g} / \mathrm{kg}$ & 1 & Satisfactory & Quasimeme & ja \\
\hline BT4 & 2016.02 & nov 2016 & QPH084BT & Chryseen & $\mu \mathrm{g} / \mathrm{kg}$ & 1.7 & Satisfactory & Quasimeme & ja \\
\hline BT4 & 2016.02 & nov 2016 & QPH083BT & Benzo(b)fluoranteen & $\mu \mathrm{g} / \mathrm{kg}$ & 2.4 & Questionable & Quasimeme & ja \\
\hline BT4 & 2016.02 & nov 2016 & QPH084BT & Benzo(b)fluoranteen & $\mu \mathrm{g} / \mathrm{kg}$ & 2.4 & Questionable & Quasimeme & ja \\
\hline BT4 & 2016.02 & nov 2016 & QPH083BT & Benzo(k)fluoranteen & $\mu \mathrm{g} / \mathrm{kg}$ & 1.6 & Satisfactory & Quasimeme & ja \\
\hline BT4 & 2016.02 & nov 2016 & QPH084BT & Benzo(k)fluoranteen & $\mu \mathrm{g} / \mathrm{kg}$ & 1.9 & Satisfactory & Quasimeme & ja \\
\hline BT4 & 2016.02 & nov 2016 & QPH083BT & Benzo(a)pyreen & $\mu \mathrm{g} / \mathrm{kg}$ & 1.8 & Satisfactory & Quasimeme & ja \\
\hline BT4 & 2016.02 & nov 2016 & QPH084BT & Benzo(a)pyreen & $\mu \mathrm{g} / \mathrm{kg}$ & 3.2 & Unsatisfactory & Quasimeme & ja \\
\hline BT4 & 2016.02 & nov 2016 & QPH083BT & Dibenz(ah)antraceen & $\mu \mathrm{g} / \mathrm{kg}$ & 2.5 & Questionable & Quasimeme & ja \\
\hline BT4 & 2016.02 & nov 2016 & QPH084BT & Dibenz(ah)antraceen & $\mu \mathrm{g} / \mathrm{kg}$ & 3.5 & Unsatisfactory & Quasimeme & ja \\
\hline BT4 & 2016.02 & nov 2016 & QPH083BT & benzo(ghi)peryleen & $\mu \mathrm{g} / \mathrm{kg}$ & 1.9 & Satisfactory & Quasimeme & ja \\
\hline BT4 & 2016.02 & nov 2016 & QPH084BT & benzo(ghi)peryleen & $\mu \mathrm{g} / \mathrm{kg}$ & 1.9 & Satisfactory & Quasimeme & ja \\
\hline BT4 & 2016.02 & nov 2016 & QPH083BT & Indeno(123)peryleen & $\mu \mathrm{g} / \mathrm{kg}$ & 3.2 & Unsatisfactory & Quasimeme & ja \\
\hline BT4 & 2016.02 & nov 2016 & QPH084BT & Indeno(123)peryleen & $\mu \mathrm{g} / \mathrm{kg}$ & 2.5 & Questionable & Quasimeme & ja \\
\hline
\end{tabular}


Rapportagegrenzen en meetonzekerheid

\begin{tabular}{|c|c|c|c|c|c|c|c|}
\hline Component & $\begin{array}{l}\text { rapportage- } \\
\text { grens }\end{array}$ & $\begin{array}{l}\text { detectie- } \\
\text { limiet }\end{array}$ & unit & $\mathrm{ng} / \mathrm{dg}$ & $\begin{array}{c}\text { vC } \\
\text { rel. standard uncertainty (\%) }\end{array}$ & $\mathrm{n}$ & dc \\
\hline PBDE28 & 0.002 & 0.001 & $\mu \mathrm{g} / \mathrm{kg}$ & $\mathrm{ng}$ & 19.3 & 11 & 0 \\
\hline PBDE47 & 0.002 & 0.001 & $\mu \mathrm{g} / \mathrm{kg}$ & $\mathrm{ng}$ & 11.8 & 22 & 0 \\
\hline PBDE66 & 0.002 & 0.001 & $\mu \mathrm{g} / \mathrm{kg}$ & $\mathrm{ng}$ & 20.0 & & 0 \\
\hline PBDE85 & 0.003 & 0.0015 & $\mu \mathrm{g} / \mathrm{kg}$ & $\mathrm{ng}$ & 20.0 & & 0 \\
\hline PBDE999 & 0.002 & 0.001 & $\mu \mathrm{g} / \mathrm{kg}$ & $\mathrm{ng}$ & 17.2 & 10 & 0 \\
\hline PBDE100 & 0.003 & 0.0015 & $\mu \mathrm{g} / \mathrm{kg}$ & $\mathrm{ng}$ & 17.9 & 18 & 0 \\
\hline PBDE153 & 0.002 & 0.001 & $\mu \mathrm{g} / \mathrm{kg}$ & $\mathrm{ng}$ & 20.0 & 9 & 0 \\
\hline PBDE154+BB153 & 0.001 & 0.00 & $\mu \mathrm{g} / \mathrm{kg}$ & $\mathrm{ng}$ & 28.4 & 12 & 0 \\
\hline PBDE183 & 0.002 & 0.00 & $\mu \mathrm{g} / \mathrm{kg}$ & $\mathrm{ng}$ & 20.0 & & 0 \\
\hline $\mathrm{HBCD}$ & 0.010 & 0.01 & $\mu \mathrm{g} / \mathrm{kg}$ & $\mathrm{ng}$ & 20.0 & & 0 \\
\hline PFBA & 1.2 & 0.60 & $\mu \mathrm{g} / \mathrm{kg}$ & $\mathrm{ng}$ & 25.0 & & 0 \\
\hline PFPeA & 0.3 & 0.15 & $\mu \mathrm{g} / \mathrm{kg}$ & $\mathrm{ng}$ & 25.0 & & 0 \\
\hline PFHXA & 0.3 & 0.15 & $\mu \mathrm{g} / \mathrm{kg}$ & $\mathrm{ng}$ & 25.0 & & 0 \\
\hline PFHpA & 0.3 & 0.15 & $\mu \mathrm{g} / \mathrm{kg}$ & $\mathrm{ng}$ & 25.0 & & 0 \\
\hline PFOA & 0.3 & 0.15 & $\mu \mathrm{g} / \mathrm{kg}$ & $\mathrm{ng}$ & $17.8^{\star}$ & 8 & 0 \\
\hline PFNA & 0.3 & 0.15 & $\mu \mathrm{g} / \mathrm{kg}$ & $\mathrm{ng}$ & 25.0 & & 0 \\
\hline PFDcA & 0.3 & 0.15 & $\mu \mathrm{g} / \mathrm{kg}$ & $\mathrm{ng}$ & 25.0 & & 0 \\
\hline PFUnA & 0.3 & 0.15 & $\mu \mathrm{g} / \mathrm{kg}$ & $\mathrm{ng}$ & 25.0 & & 0 \\
\hline PFDoA & 0.3 & 0.15 & $\mu \mathrm{g} / \mathrm{kg}$ & $\mathrm{ng}$ & 25.0 & & 0 \\
\hline PFTrA & 0.60 & 0.30 & $\mu \mathrm{g} / \mathrm{kg}$ & $\mathrm{ng}$ & 25.0 & & 0 \\
\hline PFTeA & 0.60 & 0.30 & $\mu \mathrm{g} / \mathrm{kg}$ & $\mathrm{ng}$ & 25.0 & & 0 \\
\hline PFBS & 0.50 & 0.25 & $\mu \mathrm{g} / \mathrm{kg}$ & $\mathrm{ng}$ & 25.0 & & 0 \\
\hline PFHXS & 0.50 & 0.25 & $\mu \mathrm{g} / \mathrm{kg}$ & $\mathrm{ng}$ & 25.0 & & 0 \\
\hline PFHpS & 0.5 & 0.25 & $\mu \mathrm{g} / \mathrm{kg}$ & $\mathrm{ng}$ & 25.0 & & 0 \\
\hline PFOS & 0.5 & 0.25 & $\mu \mathrm{g} / \mathrm{kg}$ & $\mathrm{ng}$ & $10.5^{*}$ & 8 & 0 \\
\hline PFDS & 0.5 & 0.25 & $\mu \mathrm{g} / \mathrm{kg}$ & $\mathrm{ng}$ & 25.0 & & 0 \\
\hline TBT als kation & 1.8 & 0.90 & $\mu \mathrm{g} / \mathrm{kg}$ & $\mathrm{ng}$ & 24.6 & 9 & 0 \\
\hline DBT als kation & 1.6 & 0.80 & $\mu \mathrm{g} / \mathrm{kg}$ & $\mathrm{ng}$ & 14.7 & 19 & 0 \\
\hline MBT als kation & 1.3 & 0.65 & $\mu \mathrm{g} / \mathrm{kg}$ & $\mathrm{ng}$ & 25.4 & 9 & 0 \\
\hline TPhT als kation & 1.8 & 0.90 & $\mu \mathrm{g} / \mathrm{kg}$ & $\mathrm{ng}$ & 25.0 & & 0 \\
\hline DPhT als kation & 1.7 & 0.85 & $\mu \mathrm{g} / \mathrm{kg}$ & $\mathrm{ng}$ & 25.0 & & 0 \\
\hline MPhT als kation & 1.4 & 0.70 & $\mu \mathrm{g} / \mathrm{kg}$ & $\mathrm{ng}$ & 25.0 & & 0 \\
\hline PCB31 & 0.08 & 0.04 & $\mu \mathrm{g} / \mathrm{kg}$ & $\mathrm{ng}$ & 12.0 & 8 & 0 \\
\hline PCB28 & 0.08 & 0.04 & $\mu \mathrm{g} / \mathrm{kg}$ & $\mathrm{ng}$ & 10.4 & 8 & 0 \\
\hline PCB52 & 0.08 & 0.04 & $\mu \mathrm{g} / \mathrm{kg}$ & $\mathrm{ng}$ & 9.3 & 8 & 0 \\
\hline PCB49 & 0.08 & 0.04 & $\mu \mathrm{g} / \mathrm{kg}$ & $\mathrm{ng}$ & 10.7 & 8 & 0 \\
\hline PCB47 & 0.08 & 0.04 & $\mu \mathrm{g} / \mathrm{kg}$ & $\mathrm{ng}$ & 13.6 & 8 & 0 \\
\hline PCB66 & 0.08 & 0.04 & $\mu \mathrm{g} / \mathrm{kg}$ & $\mathrm{ng}$ & 9.3 & 8 & 0 \\
\hline PCB101 & 0.16 & 0.08 & $\mu \mathrm{g} / \mathrm{kg}$ & $\mathrm{ng}$ & 6.3 & 8 & 0 \\
\hline PCB97 & 0.08 & 0.04 & $\mu \mathrm{g} / \mathrm{kg}$ & $\mathrm{ng}$ & 7.0 & 8 & 0 \\
\hline PCB87 & 0.08 & 0.04 & $\mu \mathrm{g} / \mathrm{kg}$ & $\mathrm{ng}$ & 16.8 & 8 & 0 \\
\hline PCB85 & 0.08 & 0.04 & $\mu \mathrm{g} / \mathrm{kg}$ & $\mathrm{ng}$ & 3.4 & 8 & 0 \\
\hline PCB110 & 0.13 & 0.07 & $\mu \mathrm{g} / \mathrm{kg}$ & $\mathrm{ng}$ & 5.4 & 8 & 0 \\
\hline PCB151 & 0.08 & 0.04 & $\mu \mathrm{g} / \mathrm{kg}$ & $\mathrm{ng}$ & 6.1 & 8 & 0 \\
\hline PCB149 & 0.18 & 0.09 & $\mu \mathrm{g} / \mathrm{kg}$ & $\mathrm{ng}$ & 8.3 & 8 & 0 \\
\hline PCB118 & 0.21 & 0.11 & $\mu \mathrm{g} / \mathrm{kg}$ & $\mathrm{ng}$ & 6.5 & 8 & 0 \\
\hline PCB153 & 0.16 & 0.08 & $\mu \mathrm{g} / \mathrm{kg}$ & $\mathrm{ng}$ & 12.5 & 8 & 0 \\
\hline PCB141 & 0.08 & 0.04 & $\mu \mathrm{g} / \mathrm{kg}$ & $\mathrm{ng}$ & 9.3 & 8 & 0 \\
\hline PCB105 & 0.08 & 0.04 & $\mu \mathrm{g} / \mathrm{kg}$ & $\mathrm{ng}$ & 7.2 & 8 & 0 \\
\hline PCB138 & 0.16 & 0.08 & $\mu \mathrm{g} / \mathrm{kg}$ & $\mathrm{ng}$ & 13.0 & 8 & 0 \\
\hline PCB187 & 0.11 & 0.06 & $\mu \mathrm{g} / \mathrm{kg}$ & $\mathrm{ng}$ & 8.9 & 8 & 0 \\
\hline PCB128 & 0.08 & 0.04 & $\mu \mathrm{g} / \mathrm{kg}$ & $\mathrm{ng}$ & 8.9 & 8 & 0 \\
\hline PCB156 & 0.11 & 0.06 & $\mu \mathrm{g} / \mathrm{kg}$ & $\mathrm{ng}$ & 7.6 & 8 & 0 \\
\hline PCB180 & 0.08 & 0.04 & $\mu \mathrm{g} / \mathrm{kg}$ & $\mathrm{ng}$ & 11.4 & 8 & 0 \\
\hline PCB170 & 0.11 & 0.06 & $\mu \mathrm{g} / \mathrm{kg}$ & $\mathrm{ng}$ & 12.8 & 8 & 0 \\
\hline PCB56 & 0.16 & 0.08 & $\mu \mathrm{g} / \mathrm{kg}$ & $\mathrm{ng}$ & 4.4 & 8 & 0 \\
\hline PCB137 & 0.05 & 0.03 & $\mu \mathrm{g} / \mathrm{kg}$ & $\mathrm{ng}$ & 8.4 & 8 & 0 \\
\hline PCB202 & 0.05 & 0.03 & $\mu \mathrm{g} / \mathrm{kg}$ & $\mathrm{ng}$ & 6.6 & 8 & 0 \\
\hline PCB194 & 0.08 & 0.04 & $\mu \mathrm{g} / \mathrm{kg}$ & $\mathrm{ng}$ & 11.7 & 8 & 0 \\
\hline PCB206 & 0.08 & 0.04 & $\mu \mathrm{g} / \mathrm{kg}$ & $\mathrm{ng}$ & 14.6 & 8 & 0 \\
\hline $\mathrm{HCBD}$ & 0.01 & 0.004 & $\mu \mathrm{g} / \mathrm{kg}$ & $\mathrm{ng}$ & 7.5 & 8 & 0 \\
\hline QCB & 0.01 & 0.004 & $\mu \mathrm{g} / \mathrm{kg}$ & $\mathrm{ng}$ & 4.9 & 8 & 0 \\
\hline $\mathrm{HCB}$ & 0.01 & 0.004 & $\mu \mathrm{g} / \mathrm{kg}$ & $\mathrm{ng}$ & 10.6 & 8 & 0 \\
\hline pp-DDE & 0.06 & 0.03 & $\mu \mathrm{g} / \mathrm{kg}$ & $\mathrm{ng}$ & 10.5 & 8 & 0 \\
\hline Heptachloor & 0.03 & 0.02 & $\mu \mathrm{g} / \mathrm{kg}$ & $\mathrm{ng}$ & 8.9 & 8 & 0 \\
\hline $\mathrm{a}-\mathrm{HCH}$ & 0.02 & 0.01 & $\mu \mathrm{g} / \mathrm{kg}$ & $\mathrm{ng}$ & 21.3 & 21 & 0 \\
\hline b-HCH & 0.04 & 0.02 & $\mu \mathrm{g} / \mathrm{kg}$ & $\mathrm{ng}$ & 22.0 & & 0 \\
\hline b-HEPO & 0.02 & 0.01 & $\mu \mathrm{g} / \mathrm{kg}$ & $\mathrm{ng}$ & 25.0 & & 0 \\
\hline Dieldrin & 0.03 & 0.02 & $\mu \mathrm{g} / \mathrm{kg}$ & $\mathrm{ng}$ & 25.0 & & 0 \\
\hline pp_DDD & 0.03 & 0.02 & $\mu \mathrm{g} / \mathrm{kg}$ & $\mathrm{ng}$ & 18.3 & 47 & 0 \\
\hline pp_DDT & 0.05 & 0.03 & $\mu \mathrm{g} / \mathrm{kg}$ & $\mathrm{ng}$ & 25.0 & & 0 \\
\hline$y-\mathrm{HCH}$ & 0.02 & 0.01 & $\mu \mathrm{g} / \mathrm{kg}$ & $\mathrm{ng}$ & 21.1 & 22 & 0 \\
\hline Kwik & 0.0008 & 0.0004 & $\mathrm{mg} / \mathrm{kg}$ & $\mathrm{ng}$ & 16.8 & 16 & 0 \\
\hline Dry-weight & 0.00037 & 0.00019 & $\mathrm{mg}$ & $\mathrm{ng}$ & 3.5 & 50 & 0 \\
\hline \begin{tabular}{|l|} 
Ash-Weight \\
\end{tabular} & 0.12 & 0.06 & $\%$ & $\mathrm{ng}$ & 9.0 & 31 & 0 \\
\hline Total-Lipid & 0.003 & 0.0015 & $\%$ & $\mathrm{ng}$ & 16.6 & 39 & 0 \\
\hline Acenafteen & 0.30 & 0.10 & $\mu \mathrm{g} / \mathrm{kg}$ & $\mathrm{ng}$ & 23.4 & 20 & 0 \\
\hline \begin{tabular}{|l|} 
Fluoreen \\
\end{tabular} & 0.90 & 0.36 & $\mu \mathrm{g} / \mathrm{kg}$ & $\mathrm{ng}$ & 19.6 & 31 & 0 \\
\hline Fenantreen & 15.90 & 6.36 & $\mu \mathrm{g} / \mathrm{kg}$ & $\mathrm{ng}$ & 17.8 & 20 & 0 \\
\hline Antraceen & 0.70 & 0.28 & $\mu \mathrm{g} / \mathrm{kg}$ & $\mathrm{ng}$ & 30.7 & 28 & 0 \\
\hline Fluoranteen & 10.20 & 4.08 & $\mu \mathrm{g} / \mathrm{kg}$ & $\mathrm{ng}$ & 13.6 & 39 & 0 \\
\hline Pyreen & 5.10 & 2.04 & $\mu \mathrm{g} / \mathrm{kg}$ & $\mathrm{ng}$ & 13.0 & 42 & 0 \\
\hline Benzo(a)antraceen & 0.70 & 0.28 & $\mu \mathrm{g} / \mathrm{kg}$ & $\mathrm{ng}$ & 21.2 & 35 & 0 \\
\hline Chryseen & 0.40 & 0.16 & $\mu \mathrm{gg} / \mathrm{kg}$ & $\mathrm{ng}$ & 19.9 & 37 & 0 \\
\hline Benzo(b)fluoranteen & 0.20 & 0.10 & $\mu \mathrm{g} / \mathrm{kg}$ & $\mathrm{ng}$ & 21.4 & 42 & 0 \\
\hline Benzo(k)fluoranteen & 0.20 & 0.10 & $\mu \mathrm{g} / \mathrm{kg}$ & $\mathrm{ng}$ & 23.0 & 32 & 0 \\
\hline Benzo(a)pyreen & 0.20 & 0.10 & $\mu \mathrm{g} / \mathrm{kg}$ & $\mathrm{ng}$ & 16.8 & 34 & 0 \\
\hline Dibenz(ah)antraceen & 0.20 & 0.10 & $\mu \mathrm{g} / \mathrm{kg}$ & $\mathrm{ng}$ & 30.6 & 9 & 0 \\
\hline benzo(ghi)peryleen & 0.20 & 0.10 & $\mu \mathrm{g} / \mathrm{kg}$ & $\mathrm{ng}$ & 22.0 & 36 & 0 \\
\hline Indeno(123)peryleen & 0.20 & 0.10 & $\mu \mathrm{g} / \mathrm{kg}$ & $\mathrm{ng}$ & 28.3 & 26 & 0 \\
\hline
\end{tabular}

\begin{tabular}{|l|c|c|c|c|c|}
\hline Component & $\begin{array}{c}\text { rapportage- } \\
\text { grens Triskelion }\end{array}$ & unit & $\mathrm{ng} / \mathrm{dg}$ & $\begin{array}{c}\text { meetonzekerheid (\%) } \\
\text { Triskelion }\end{array}$ & \\
\hline Cadmium & 0.0003 & $\mathrm{mg} / \mathrm{kg}$ & $\mathrm{ng}$ & $8.7 \%$ op niveau van $1.3 \mathrm{mg} / \mathrm{kg}$ & 0 \\
\hline Zink & 0.25 & $\mathrm{mg} / \mathrm{kg}$ & $\mathrm{ng}$ & $8.5 \%$ op niveau van $69 \mathrm{mg} / \mathrm{kg}$ & 0 \\
\hline Koper & 0.015 & $\mathrm{mg} / \mathrm{kg}$ & $\mathrm{ng}$ & $9.0 \%$ op niveau van $4.4 \mathrm{mg} / \mathrm{kg}$ & 0 \\
\hline Lood & 0.007 & $\mathrm{mg} / \mathrm{kg}$ & $\mathrm{ng}$ & $10 \%$ op niveau van $1.4 \mathrm{mg} / \mathrm{kg}$ & 0 \\
\hline Chroom & 0.007 & $\mathrm{mg} / \mathrm{kg}$ & $\mathrm{ng}$ & $13 \%$ op niveau van $0.065 \mathrm{mg} / \mathrm{kg}$ & 0 \\
\hline Nikkel & 0.012 & $\mathrm{mg} / \mathrm{kg}$ & $\mathrm{ng}$ & $13 \%$ op niveau van $0.2 \mathrm{mg} / \mathrm{kg}$ & 0 \\
\hline Arseen & 0.005 & $\mathrm{mg} / \mathrm{kg}$ & $\mathrm{ng}$ & $17 \%$ op niveau van $1.4 \mathrm{mg} / \mathrm{kg}$ & 0 \\
\hline
\end{tabular}

op basis van juistheidsbepaling en monsterinhomogeniteit

verwaarloosbaar klein

izen aan de hand waarvan een Z-score bepaald kon worden

列

*Meetonzekerheid gebaseerd op de RMS van juistheidbepaling en de inhomogeniteitsbijdrage van de praktijkmonsters 

Wageningen Marine Research

T: +31(0)317480900

E: marine-research@wur.nl

www.wur.nl/marine-research

Visitors address

- Ankerpark 271781 AG Den Helder

- Korringaweg 7, 4401 NT Yerseke

- Haringkade 1, 1976 CP IJmuiden
Wageningen Marine Research is the Netherlands research institute established to provide the scientific support that is essential for developing policies and innovation in respect of the marine environment, fishery activities, aquaculture and the maritime sector.

Wageningen University \& Research is specialised in the domain of healthy food and living environment.

The Wageningen Marine Research vision:

'To explore the potential of marine nature to improve the quality of life.'

The Wageningen Marine Research mission

- To conduct research with the aim of acquiring knowledge and offering advice on the sustainable management and use of marine and coastal areas.

- Wageningen Marine Research is an independent, leading scientific research institute.

Wageningen Marine Research is part of the international knowledge organisation Wageningen UR (University \& Research centre). Within Wageningen UR, nine specialised research institutes of Stichting Wageningen Research (a Foundation) have joined forces with Wageningen University to help answer the most important questions in the domain of healthy food and living environment. 